\title{
DNA barcoding of Aphelopus Dalman (Hymenoptera, Dryinidae) from China, with descriptions of four new species
}

\author{
Massimo OLMI ${ }^{1}$, Hua-Yan CHEN ${ }^{\circledR 2, *}$, Adalgisa GUGLIELMINO ${ }^{3}$, Frode ØDEGAARD ${ }^{4}$, \\ Massimo VOLLARO ${ }^{5}$, Leonardo CAPRADOSSI ${ }^{6} \&$ Jing-Xian LIU ${ }^{7}$ \\ ${ }^{1}$ Tropical Entomology Research Center, Via De Gasperi 10, 01100 Viterbo, Italy. \\ ${ }^{2}$ Key Laboratory of Plant Resources Conservation and Sustainable Utilization, \\ South China Botanical Garden, Chinese Academy of Sciences, Guangzhou 510650, China. \\ 3,5 Department of Agriculture and Forest Sciences (DAFNE), \\ University of Tuscia, 01100 Viterbo, Italy. \\ ${ }^{4}$ Norwegian University of Science and Technology (NTNU), Department of Natural History, \\ NO-7491 Trondheim, Norway. \\ ${ }^{6}$ Via Pericle Scriboni 28, 01017 Tuscania, Italy. \\ ${ }^{7}$ Department of Entomology, College of Plant Protection, South China Agricultural University, \\ Guangzhou 510642, China. \\ *Corresponding author: huayanc@scbg.ac.cn \\ ${ }^{1}$ Email: olmimassimo@gmail.com \\ ${ }^{3}$ Email: guglielm@unitus.it \\ ${ }^{4}$ Email: frode.odegaard@ntnu.no \\ ${ }^{5}$ Email: vollaro@unitus.it \\ ${ }^{6}$ Email: leonardocapradossi.lc@gmail.com \\ ${ }^{7}$ Email: liujingxian@scau.edu.cn

\footnotetext{
${ }^{1}$ urn:lsid:zoobank.org:author:147A9DA2-415F-4E17-8546-DEEEAB9230A9

${ }^{2}$ urn:lsid:zoobank.org:author:CDB89961-BBC3-412B-BE7F-B3B9E290B991

${ }^{3}$ urn:lsid:zoobank.org:author:1EAE4622-8F64-484C-B439-76F9838F936F

${ }^{5}$ urn:lsid:zoobank.org:author:133EA7D3-0560-4CF2-973F-815E3F10CD32

${ }^{6}$ urn:lsid:zoobank.org:author:3F870526-E9B2-4318-A094-1533029AB6D3

${ }^{7}$ urn:lsid:zoobank.org:author:9465CC48-7A17-405A-AB27-2575A603AA3A
} \\ ${ }^{4}$ urn:lsid:zoobank.org:author:31BDDDCD-CA33-403F-AC01-2C769ADD08D4
}

\begin{abstract}
Species of the genus Aphelopus Dalman (Hymenoptera, Dryinidae) are important natural enemies of leafhoppers. The genus is relatively diverse in China, with 35 recorded species. In order to further make use of these important parasitoids in biological control programs, species of Aphelopus collected across China are studied using an integrative approach (combined DNA barcoding and morphology). Of the 17 studied species, two are newly recorded from China: A. nivealis Mita \& Olmi, 2014 and A. prolatus Mita \& Olmi, 2014, and four are described as new to science: A. incognitus Chen, Olmi \& Guglielmino sp. nov., A. maculiala Olmi, Chen \& Ødegaard sp. nov., A. taianensis Olmi, Ødegaard \& Chen sp. nov., and A. zaifui Olmi, Chen \& Liu sp. nov. The total number of Aphelopus species known from China is raised from 35 to 39. Keys to the Oriental and Eastern Palaearctic species
\end{abstract}


of Aphelopus are modified to include the new species. Application of DNA barcoding in the species delimitation of Dryinidae is discussed.

Keywords. Chrysidoidea, Oriental, Eastern Palaearctic, identification key, COI gene.

Olmi M., Chen H.-Y., Guglielmino A., Ødegaard F., Vollaro M., Capradossi L. \& Liu J.-X. 2022. DNA barcoding of Aphelopus Dalman (Hymenoptera, Dryinidae) from China, with descriptions of four new species. European Journal of Taxonomy 794: 40-71. https://doi.org/10.5852/ejt.2022.794.1653

\section{Introduction}

Aphelopus Dalman, 1823 (Hymenoptera, Dryinidae) is a cosmopolitan genus of parasitoids attacking Typhlocybinae Kirschbaum, 1868 (Hemiptera, Cicadellidae). Many of their hosts are important insect pests (Guglielmino et al. 2013). The genus comprises 78 species (Guglielmino et al. 2017), present in all the zoogeographic regions except Antarctica. Xu et al. (2013) and Guglielmino et al. (2017) listed 30 species from the Oriental region, of which 29 are from China. Olmi \& Xu (2015) added further six species from Eastern Palaearctic China, bringing the total number of species known from China to 35 .

Further development of these important parasitoids in biological control programs against leafhoppers requires accurate identification of the species. However, the taxonomy of Dryinidae Haliday, 1833 is challenging because many species are morphologically similar and require a careful examination of detailed morphological characters, especially the male genitalia. Intraspecific morphological variation and extreme sexual dimorphism are the two main issues which hamper research on the systematics of Dryinidae (Olmi et al. 2021), including that of the genus Aphelopus. In addition, too few researchers rear dryinids and many species were described based on a single specimen or a small number of specimens, making it difficult to understand if a morphological or colour difference falls within the range of variability of a species or indicates a new taxon. The lack of rearing also means that it is difficult to associate conspecifics based on morphology, as males and females of the same species are usually completely different. DNA markers, such as the mitochondrial cytochrome $\mathrm{c}$ oxidase $1(\mathrm{COI})$ gene, have become an important species identification tool for insects (Hebert et al. 2003a, 2003b). The importance of DNA sequences in the taxonomy and systematics of Dryinidae as well as the molecular identification of their host associations has been recognized by some researchers (see Mita \& Matsumoto 2012; Mita et al. 2013; Tribull 2015; Chen et al. 2020; Olmi et al. 2021). By analyzing COI sequences, Mita \& Matsumoto (2012) discovered the male of Gonatopus javanus (Perkins, 1912), a species previously known only from females. Similarly, based on COI sequences, Mita et al. (2013) found that Haplogonatopus oratorius (Westwood, 1833) and H. apicalis Perkins, 1905, whose females and males had previously been confused, were separate species. In addition, Chen et al. (2020) discovered the previously unknown host of Gonatopus viet Olmi, 1986, by a comparison of COI sequences of females and immature larvae extracted from host thylacia. More recently, Olmi et al. (2021) associated female, male, larva, and the host of Bocchus scobiolae Nagy, 1967, by COI sequences.

However, a DNA barcode database is still lacking for the Chinese fauna of Dryinidae. To fill this gap, one of the coauthors $(\mathrm{HC})$ started a research campaign with the objectives to collect specimens of dryinids across China, identify the species by morphological characters and build a DNA database for these important parasitoids. This paper is the first result of the ongoing research campaign.

\section{Material and methods}

\section{Collection and identification}

Malaise traps (MT) have been set up in many provinces of China (Fig. 1). Specimens were kept in $100 \%$ ethanol and collected monthly. Samples were then brought to the laboratory and stored at $-20^{\circ} \mathrm{C}$. The 
species of Aphelopus were identified using the available keys present in Xu et al. (2013) and Olmi \& Xu (2015) and based on morphological characters.

\section{Repositories}

The material from China studied in this paper is deposited in the Museum of Biology at Sun Yat-sen University, Guangzhou, China (SYSBM) and the South China Agricultural University, Guangzhou, China (SCAU). The specimen numbers start with SCAU when they were donated by SCAU to SYSBM. Specimens of A. atratus (Dalman, 1823) and A. prolatus Mita \& Olmi, 2014, respectively from Norway and Sweden, are deposited in the University Museum, Norwegian University of Science and Technology, Trondheim, Norway (NTNU) and Naturhistoriska Riksmuseet, Stockholm, Sweden (NHRS), respectively. All the types of the species of Aphelopus known from the Oriental and Palaearctic regions were examined by direct observation.

\section{Descriptions}

Species descriptions follow the terminology used by Olmi et al. (2019). The measurements reported are relative, except for the total body length (head to abdominal tip, without the antenna and the sting), expressed in millimeters. In the descriptions POL is the distance between inner edges of the lateral ocelli; OL is the distance between inner edges of a lateral ocellus and the median ocellus; OOL is the distance from the outer edge of a lateral ocellus to the eye; OPL is the distance from the posterior

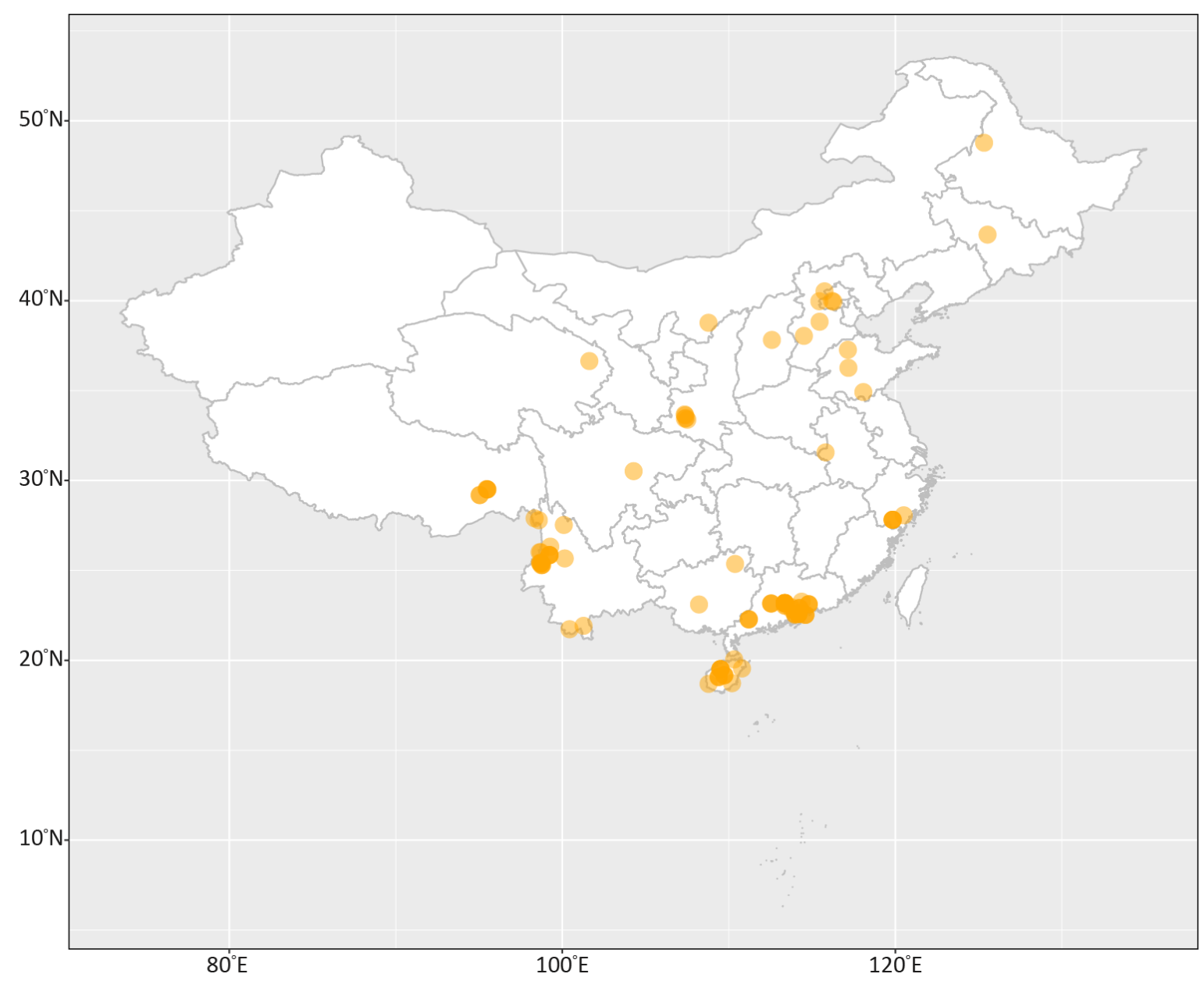

Fig. 1. Distribution map of Malaise traps set up in China. Each orange dot represents one trap. 
edge of a lateral ocellus to the occipital carina; TL is the distance from the posterior edge of an eye to the occipital carina. The term "metapectal-propodeal disc" is here used in the sense of Kawada et al. (2015). It corresponds to the term "dorsal surface of propodeum" sensu Olmi \& Xu (2015) and Xu et al. (2013). The term "propodeal declivity" sensu Kawada et al. (2015), used here, corresponds to the term "posterior surface of propodeum", sensu Xu et al. (2013) and Olmi \& Xu (2015).

\section{Imaging}

Multifocal images were made using a mirrorless Sony Alpha 6300 camera with cross table Proxxon KT 70 or a Leica M205C multifocal equipment and a Nikon SMZ25 microscope with a Nikon DS-Ri 2 digital camera system. Images were then post-processed with Adobe Photoshop CS6 Extended.

\section{COI barcoding}

Genomic DNA of the material from China was extracted from the entire specimen using a DNeasy Blood \& Tissue Kit (QIAGEN, Inc.), following a nondestructive DNA extraction protocol as described in Taekul et al. (2014). Voucher specimens (Supp. File 1) are deposited in the Museum of Biology at Sun Yat-sen University, Guangzhou, China (SYSBM). The 'barcode' region of the mitochondrial cytochrome oxidase subunit 1 (COI) was amplified using the LCO1490/HCO2198 primer pair (Folmer et al. 1994). Polymerase chain reactions (PCRs) were performed using Tks Gflex ${ }^{\mathrm{TM}}$ DNA Polymerase (Takara) and conducted in a $\mathrm{T} 100^{\mathrm{TM}}$ Thermal Cycler (Bio-Rad). Thermocycling conditions were as follows: an initial denaturing step at $94^{\circ} \mathrm{C}$ for $1 \mathrm{~min}$, followed by 5 cycles of $98^{\circ} \mathrm{C}$ for $10 \mathrm{~s}, 45^{\circ} \mathrm{C}$ for $15 \mathrm{~s}, 68^{\circ} \mathrm{C}$ for $30 \mathrm{~s}$; 35 cycles of $98^{\circ} \mathrm{C}$ for $10 \mathrm{~s}, 52^{\circ} \mathrm{C}$ for $15 \mathrm{~s}, 68^{\circ} \mathrm{C}$ for $30 \mathrm{~s}$ and an additional extension at $68^{\circ} \mathrm{C}$ for 5 mins. Amplicons were directly sequenced in both directions with forward and reverse primers on an Applied Biosystem (ABI) 3730XL by TsingKe Biological Technology (Beijing, China). Chromatograms were assembled into contigs in Geneious ver. 11.0.3. The assembled sequences were translated to amino acids using the invertebrate mitochondrial code to check for stop codons and frame shifts, and were blasted against the GenBank database to check for contamination and pseudogenes (e.g., nuclear mitochondrial DNA, NUMT) as implemented in Geneious ver. 11.0.3. All sequences generated from this study are deposited in GenBank (accession numbers see Table 1), except the sequences of Aphelopus atratus (Dalman, 1823) and A. prolatus Mita \& Olmi, 2014, respectively from Norway and Sweden, which are uploaded in the BOLD System (Ratnasingham \& Hebert 2007): sequence ID for Aphelopus prolatus: NSMTP249-15.COI-5P; for Aphelopus atratus: NODRY067-14.COI-5P.

COI sequences were aligned by codons using MUSCLE implemented in MEGA7 (Kumar et al. 2016). The aligned sequences were then analyzed using RAxML as implemented in Geneious ver. 11.0.3 to generate a maximum likelihood (ML) tree. The model used was GTRGAMMA+I. Automatic bootstopping criterion was selected as the appropriate number of bootstraps; 300 replicates were run. Bocchus thorpei Olmi, 2007 (Hymenoptera, Dryinidae), from New Zealand, was used as an out-group based on the phylogenetic topologies recovered by Tribull (2015) (COI sequence of B. thorpei was downloaded from GenBank, NZAC04036596).

\section{Results}

\section{Molecular analysis}

The present study generated 23 COI sequences with an average of $658 \mathrm{bp}$. Including the sequences of A. atratus and $A$. prolatus, the 25 studied $C O I$ sequences were found to belong to 17 species, of which four are described as new below. Genetic distances of the sequences are in Supp. file 1. Intraspecific distances of the $C O I$ sequences generally are less than $3 \%$, with the exception of $A$. prolatus, which has two haplogroups (from Sweden and China, respectively) and the distance between the two haplogroups is $5.6 \%$. Interspecific distances range between $5.6 \%$ and $25.4 \%$. Each species recovered on the tree is clearly separated from all neighboring species, as shown in Fig. 2. 


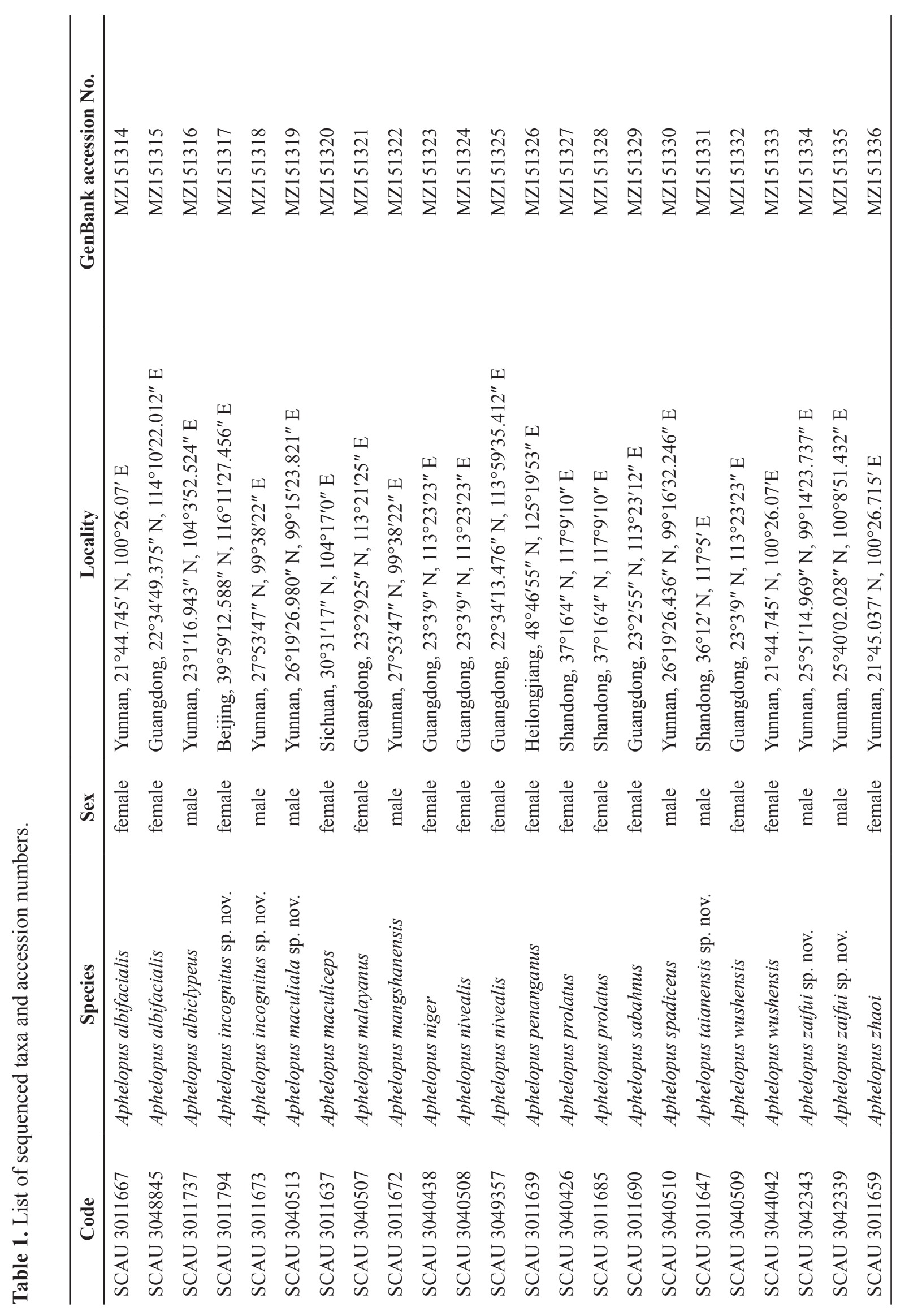


OLMI M. et al., Barcoding of Aphelopus from China

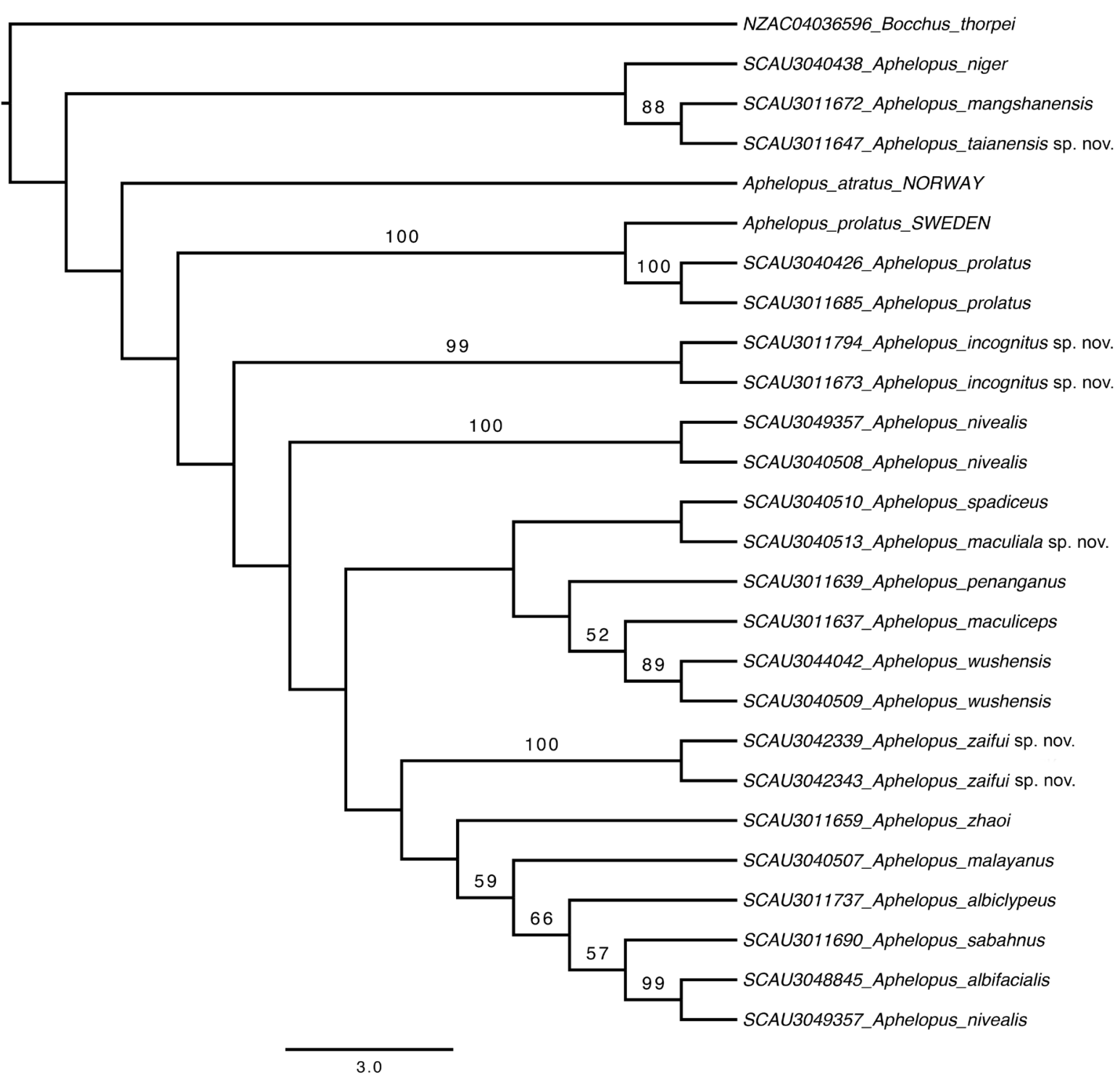

Fig. 2. Maximum likelihood tree demonstrating the clustering of Aphelopus Dalman, 1823 COI barcodes. Bootstraps values of 50 and above are indicated.

\section{Taxonomy}

Class Insecta Linnaeus, 1758

Order Hymenoptera Linnaeus, 1758

Superfamily Chrysidoidea Latreille, 1802

Family Dryinidae Haliday, 1833

Subfamily Aphelopinae Perkins, 1912

Genus Aphelopus Dalman, 1823

See Xu et al. (2013) and Olmi \& Xu (2015) for taxonomic details on the genus. 
Aphelopus incognitus Chen, Olmi \& Guglielmino sp. nov. urn:1sid:zoobank.org:act:A917F029-3AF2-451F-9B6B-CC215432441C

Figs 3-4, 8A

\section{Diagnosis}

Female with head mostly testaceous, mesosoma mostly brown, notauli reaching about $0.6 \times$ length of mesoscutum (Fig. 4D); OPL longer than OOL (Fig. 4C); frontal line incomplete, absent in front of anterior ocellus. Male with head black, antennal setae much shorter than breadth of antennomeres, mesosoma black, notauli reaching about $0.75-0.80 \times$ length of mesoscutum, fore wing hyaline, metasoma browntestaceous, basivolsella with outer process and two subdistal bristles (Fig. 8A).

\section{Etymology}

The species is named 'incognitus' (Latin adjective meaning 'unknown') because it was first recognized as a new species by $C O I$ sequences. Otherwise it would remain unnoticed, because morphologically it is extremely similar to closely related species such as A. maculiclypeus $\mathrm{Xu}, \mathrm{He} \& \mathrm{Olmi}, 1999$ and A. spadiceus Xu \& He, 1997.

\section{Material examined}

\section{Holotype}

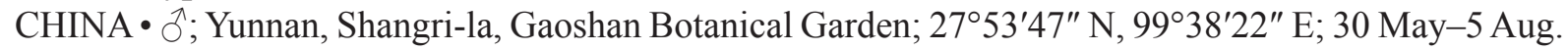
2018; Jie Zeng leg.; MT; SCAU 3011673 (SYSBM).

\section{Paratypes}

CHINA - 2 우 ; Beijing, Haidian District, Xiangshan Park; 195 m a.s.l.; $39.98683^{\circ}$ N, $116.19096^{\circ}$ E; 21-28 Aug. 2012; Li-Zhou Song and Wan-Guang Du leg.; MT; SCAU 3011794, SCAU 3040705 (SYSBM) • 1 क; same locality as for preceding; 28 Aug.-4 Sep. 2012; SCAU 3040691 (SYSBM).

\section{Description}

\section{Male (Fig. 3)}

Fully winged (Fig. 3A-B); length $2.1 \mathrm{~mm}$. Head black, except mandible testaceous; antenna brown; mesosoma black; metasoma and legs brown-testaceous. Antenna filiform; antennal setae much shorter than breadth of antennomeres; antennomeres in following proportions: 5:4:5:6:6:7:6:7:7:9. Head (Fig. 3C) dull, granulate; frontal line incomplete, absent in front of anterior ocellus; $\mathrm{POL}=6$; $\mathrm{OL}=3$; $\mathrm{OOL}=4 ; \mathrm{OPL}=3 ; \mathrm{TL}=4$; greatest breadth of lateral ocellus as long as $\mathrm{OL}$; occipital carina complete, not excavated behind the ocellar triangle. Mesoscutum and mesoscutellum dull, granulate. Notauli incomplete, reaching approximately $0.7 \times$ length of mesoscutum (Fig. 3D). Metanotum unsculptured. Metapectal-propodeal complex with disc dull, reticulate rugose; propodeal declivity with two longitudinal keels, median area shiny, unsculptured and lateral areas rugose. Fore wing hyaline, without dark transverse bands. Basivolsella (Fig. 8A) with two subdistal bristles and outer medial process. Tibial spurs $1 / 1 / 2$.

\section{Female (Fig. 4)}

Fully winged (Fig. 4A-B); length $1.9 \mathrm{~mm}$. Head (Fig. 4C) testaceous, except large brown spot on temple, vertex and posterior half of frons (with short testaceous arms along orbits); antenna brown, except scape and pedicel yellow; mesosoma dark brown, except propleuron and lateral regions of pronotum testaceous; metasoma brown-testaceous; legs testaceous. Antenna clavate; antennomeres in following proportions: 5:4:5:5:5:5:4:4:4:7. Head dull, granulate; frontal line incomplete, absent in front of anterior ocellus; $\mathrm{POL}=5 ; \mathrm{OL}=4 ; \mathrm{OOL}=4 ; \mathrm{OPL}=5 ; \mathrm{TL}=3$; greatest breadth of lateral ocellus shorter than OPL (2:5); occipital carina complete, not excavated behind ocellar triangle. Mesoscutum dull, granulate. 
Notauli incomplete, reaching about $0.6 \times$ length of mesoscutum (Fig. 4D). Mesoscutellum dull, slightly granulate. Metanotum shiny, unsculptured. Disc of metapectal-propodeal complex reticulate rugose; propodeal declivity with two longitudinal keels, median area shiny and unsculptured and lateral areas rugose. Fore wing hyaline, without dark transverse bands. Tibial spurs 1/1/2.

\section{Remarks}

The female and male association of the new species is supported by the COI sequences, which are $99.2 \%$ identical between both sexes. This new species has been collected both in the Oriental (Yunnan) and Eastern Palaearctic (Beijing) region. In the Oriental region, following the above diagnosis, the female of A. incognitus Chen, Olmi \& Guglielmino sp. nov. is close to that of $A$. ochreus Olmi, 1984. However, in the new species, the notauli reach about $0.6 \times$ length of mesoscutum (Fig. 4D); OPL is longer than OOL (Fig. 4C); the frontal line is incomplete, absent in front of the anterior ocellus (in A. ochreus, the notauli are complete or reaching about $0.75-0.80 \times$ length of mesoscutum; OPL is shorter than OOL; the frontal line is complete). Following the description of $A$. incognitus Chen, Olmi \& Guglielmino sp. nov., the key to females of Oriental Aphelopus published by Xu et al. (2013) should be modified by replacing couplet 4 as follows.

4. Notauli complete or reaching about $0.6-0.8 \times$ length of mesoscutum (Fig. 4D) 4

- Notauli reaching at most $0.5 \times$ length of mesoscutum

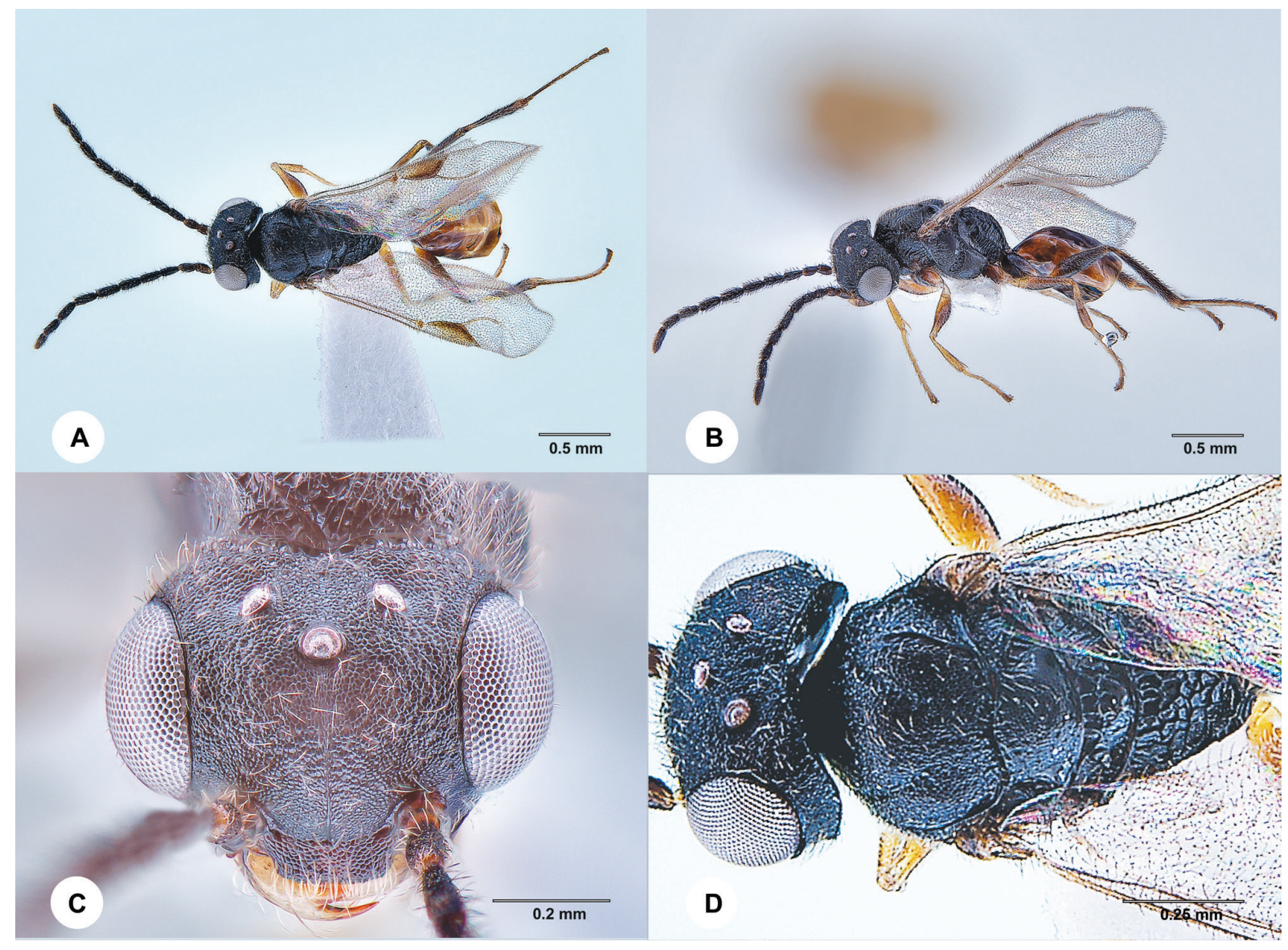

Fig. 3. Aphelopus incognitus Chen, Olmi \& Guglielmino sp. nov., ${ }^{\lambda}$, holotype (SCAU 3011673). A. Habitus, dorsal view. B. Habitus, lateral view. C. Head, frontal view. D. Head and mesosoma, dorsal view. 
4'. Notauli complete, or reaching about $0.75-0.80 \times$ length of mesoscutum; OPL shorter than OOL; frontal line complete

- Notauli incomplete, reaching about $0.6 \times$ length of mesoscutum (Fig. 4D); OPL longer than OOL (Fig. 4C); frontal line incomplete, absent in front of anterior ocellus

A. incognitus Chen, Olmi \& Guglielmino sp. nov.

In the same Oriental region, following the above diagnosis, the male of $A$. incognitus Chen, Olmi \& Guglielmino sp. nov. is close to that of A. maculiclypeus Xu, He \& Olmi, 1999. However, in A. incognitus Chen, Olmi \& Guglielmino sp. nov., POL is less than twice as long as OPL (Fig. 3C) and OPL is about as long as greatest breadth of lateral ocellus (in A. maculiclypeus, POL twice as long as OPL and OPL about twice as long as greatest breadth of lateral ocellus). Following the description of $A$. incognitus Chen, Olmi \& Guglielmino sp. nov., the key to males of Oriental Aphelopus published by Xu et al. (2013) should be modified by replacing couplet 29 as follows.

29. Antennal setae much shorter than breadth of antennomeres (Fig. 3A) $29^{\prime}$

- Antennal setae about as long as breadth of antennomeres

29'. Head with POL twice as long as OPL; OPL about twice as long as greatest breadth of lateral ocellus A. maculiclypeus Xu, He \& Olmi, 1999

- Head with POL less than twice as long as OPL (Fig. 3C); OPL about as long as greatest breadth of lateral ocellus A. incognitus Chen, Olmi \& Guglielmino sp. nov.

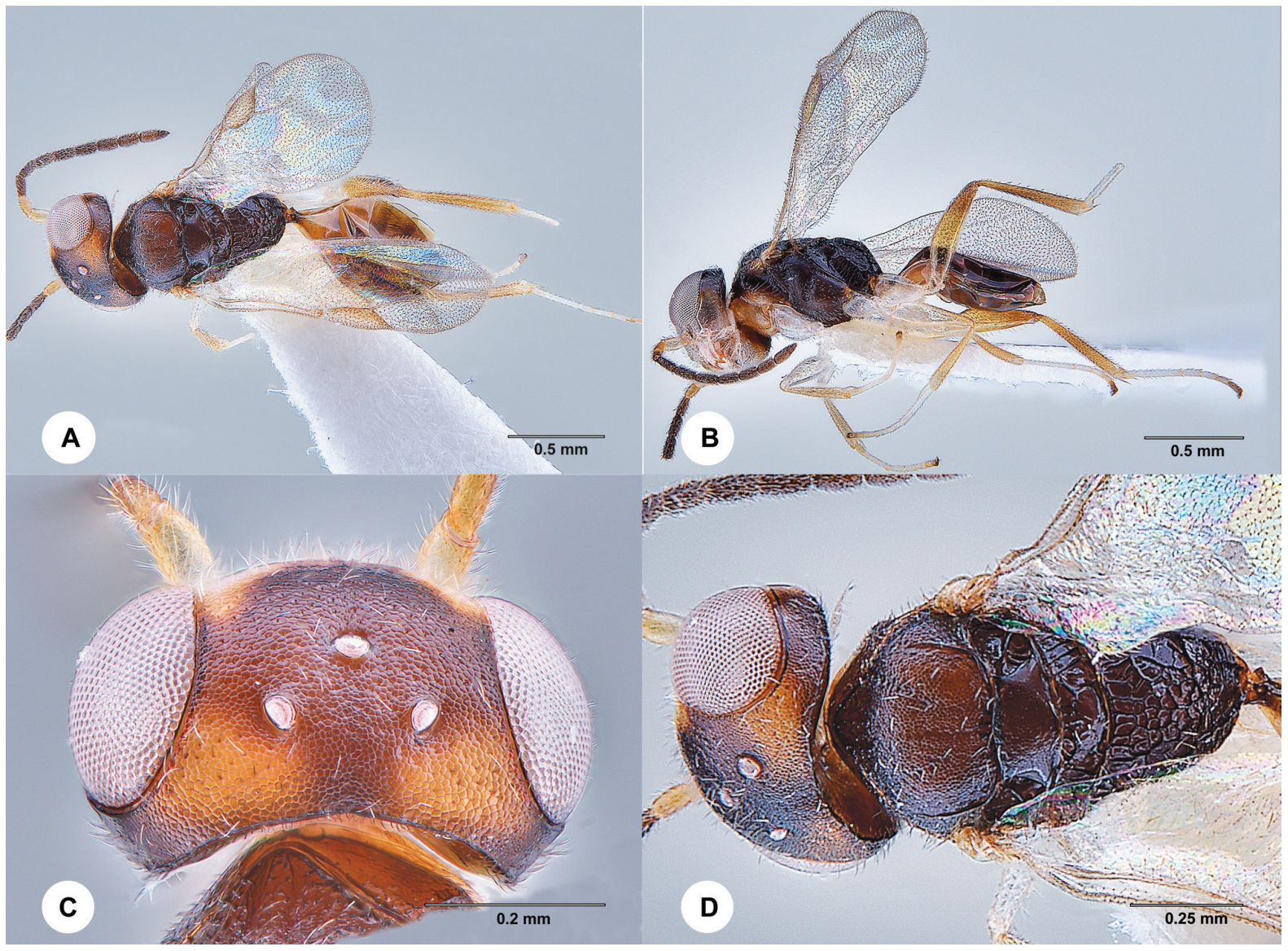

Fig. 4. Aphelopus incognitus Chen, Olmi \& Guglielmino sp. nov.,, , paratype (SCAU 3011794). A. Habitus, dorsal view. B. Habitus, lateral view. C. Head, dorsal view. D. Head and mesosoma, dorsal view. 
In the Eastern Palaearctic region, following the above diagnosis, the female of $A$. incognitus Chen, Olmi \& Guglielmino sp. nov. is close to that of A. maetoi Olmi, 1995. However, in A. incognitus Chen, Olmi \& Guglielmino sp. nov., the frontal line (Fig. 3C) is incomplete, absent in front of anterior ocellus, whereas in A. maetoi it is complete. Following the description of $A$. incognitus Chen, Olmi \& Guglielmino sp. nov., the key to females of Eastern Palaearctic Aphelopus published by Olmi \& Xu (2015) should be modified by replacing couplet 8 as follows:

8. Head with almost entire face white or testaceous (Olmi \& Xu 2015: pl. 5d)

A. querceus Olmi, 1984

- Head with anterior third or half of face white or testaceous (Fig. 4C)

8'. Frontal line complete

A. maetoi Olmi, 1995

- Frontal line incomplete, absent in front of anterior ocellus (Fig. 4C)

A. incognitus Chen, Olmi \& Guglielmino sp. nov.

In the same Eastern Palaearctic region, following the above diagnosis, the male of $A$. incognitus Chen, Olmi \& Guglielmino sp. nov.is close to that of A. spadiceus Xu \& He in Xu et al., 1997. However, in A. incognitus Chen, Olmi \& Guglielmino sp. nov., the basivolsella shows an outer process in medial position (Fig. 8A), whereas it is in distal position in A. spadiceus (Olmi \& Xu 2015: pl. 5j). Following the description of $A$. incognitus, Chen, Olmi \& Guglielmino sp. nov. the key to males of Eastern Palaearctic Aphelopus published by Olmi \& Xu (2015) should be modified by replacing couplet 9 as follows:

9. Frontal line complete

A. querceus Olmi, 1984

- Frontal line widely incomplete, not present near clypeus, or almost complete, not present in front of anterior ocellus (Fig. 3C)

9'. Basivolsella with outer basal process located in distal position (Fig. 8E)

A. spadiceus Xu \& He, 1997

- Basivolsella with outer basal process located in medial position (Fig. 8A)

A. incognitus Chen, Olmi \& Guglielmino sp. nov.

Aphelopus maculiala Olmi, Chen \& Ødegaard sp. nov. urn:lsid:zoobank.org:act:F4CFEE19-3614-417C-B703-BB7F5D0762BB

Figs $5,8 \mathrm{~B}$

\section{Diagnosis}

Male with head and mesosoma black, notauli reaching about $0.7 \times$ length of mesoscutum (Fig. 5C), fore wing with one infuscate patch beneath pterostigma (Fig. 5F), metasoma black to dark brown, distivolsella not in the form of a long straight rod (Fig. 8B); basivolsella with distal apex not widened (Fig. 8B).

\section{Etymology}

The specific name is a composition of the Latin names 'macula' (= 'spot') and 'ala' (= 'wing').

\section{Material examined}

Holotype

CHINA - O'; Yunnan, Lanping Dist., Mt Lasha; $26.324161^{\circ}$ N, $99.256617^{\circ}$ E; 2700 m a.s.1.; 10-20 Jul. 2018; Jin-Ku Li leg.; boskage; MT; SCAU 3040513 (SYSBM).

\section{Paratype}

CHINA • 1 o; Yunnan, Tengchong, Jietou; 12 May 2009; Jie Zeng leg.; SCAU 3049744 (SYSBM). 


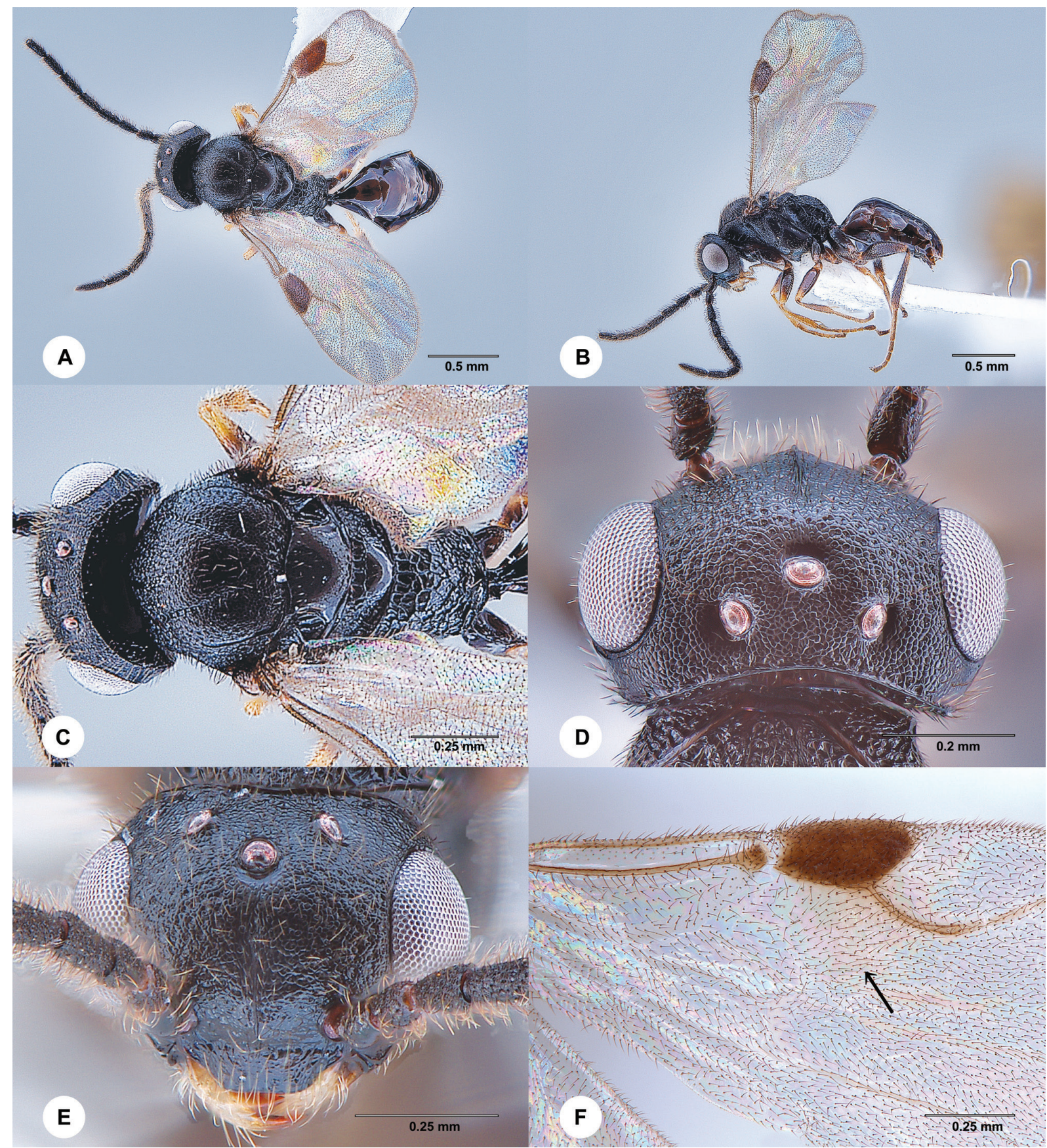

Fig. 5. Aphelopus maculiala Olmi, Chen \& Ødegaard sp. nov., Ô, holotype (SCAU 3040513). A. Habitus, dorsal view. B. Habitus, lateral view. C. Head and mesosoma, dorsal view. D. Head, dorsal view. E. Head, frontal view. F. Fore wing, arrow shows infuscate patch beneath pterostigma. 


\section{Description}

Male

Fully winged (Fig. 5A-B); length $2.3 \mathrm{~mm}$. Head black, except mandible testaceous; antenna brownblack; mesosoma black; metasoma black to dark brown; leg black to dark brown, except tarsus and fore tibia testaceous. Antenna filiform, with setae about as long as breadth of antennomeres; antennomeres in following proportions: 5:5:6:7:7:8:8:7:8:12; length/breadth ratio of ninth antennomere: $8: 2$. Head (Fig. 5D-E) dull, granulate; frontal line incomplete, shortly absent in front of anterior ocellus; $\mathrm{POL}=7$; $\mathrm{OL}=3 ; \mathrm{OOL}=5 ; \mathrm{OPL}=2 ; \mathrm{TL}=4$; greatest breadth of lateral ocellus about as long as OPL; occipital carina complete. Mesoscutum dull, granulate. Notauli incomplete, reaching about $0.7 \times$ length of mesoscutum (Fig. 5C). Mesoscutellum and metanotum shiny, unsculptured. Metapectal-propodeal disc reticulate rugose; propodeal declivity with two longitudinal keels and median area shiny, unsculptured. Fore wing (Fig. 5F) hyaline, except a small infuscate patch beneath pterostigma. Basivolsella (Fig. 8B) with distal outer process and two subdistal bristles; distal apex of aedeagus not tridentate. Tibial spurs $1 / 1 / 2$.

\section{Female}

Unknown.

\section{Remarks}

According to Xu et al. (2013), the male of Aphelopus spadiceus usually has a hyaline fore wing, except a specimen from China (Yunnan, Tengchong, Jietou, 12.v.2009, Jie Zeng leg., 1 o, SCAU) showing a small infuscate patch beneath the pterostigma. The above specimen has been considered only a variety of $A$. spadiceus by Xu et al. (2013). However, a comparison between COI sequences of two males of A. spadiceus from China, $26.324161^{\circ} \mathrm{N}, 99.256617^{\circ} \mathrm{E}$, one with a hyaline fore wing and the other with an infuscate patch (Fig. 5F), showed that the two specimens belong to two separate species. This result persuaded us to describe the specimen with an infuscate patch on the fore wing as a new species named A. maculiala Olmi, Chen \& Ødegaard sp. nov. (although the genitalia of the new species is similar to that of $A$. spadiceus). The fore wing of the new species shows a small infuscate patch, so that it is more similar to A. xanthopus Xu, He \& Olmi, 1999, than to A. spadiceus. However, in A. maculiala Olmi, Chen \& Ødegaard sp. nov. the face is completely black (Fig. 5D), whereas in A. xanthopus it is whitish between the antennal toruli. Following the description of A. maculiala Olmi, Chen \& Ødegaard sp. nov., the key to males of the Oriental Aphelopus published by Xu et al. (2013) should be modified by replacing couplet 21 as follows:

20. Fore wing with one infuscate patch beneath pterostigma (Fig. 5A) ............................................ 21

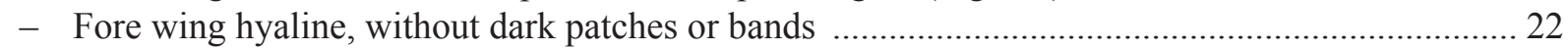

21. Face with area between antennal toruli whitish .......................... xanthopus Xu, He \& Olmi, 1999

- Face completely black (Fig. 5D) ............................... maculiala Olmi, Chen \& Ødegaard sp. nov.

Aphelopus taianensis Olmi, Ødegaard \& Chen sp. nov. urn:1sid:zoobank.org:act:407CE45D-7B8C-426C-9145-A2A45E9BE81C

Figs 6, 8C

\section{Diagnosis}

Male with head black, except mandible testaceous; mesosoma black; notauli incomplete, reaching approximately $0.5 \times$ length of mesoscutum; aedeagus distally not tridentate (Fig. $8 \mathrm{C}$ ); basivolsella very narrow (Fig. 8C), without distal outer process, with two subdistal bristles and one lateral outer pointed apophysis; distivolsella not in the form of a long straight rod. 


\section{Etymology}

The new species is named after Taian City, where it has been collected.

\section{Material examined}

\section{Holotype}

CHINA • ${ }^{\top}$; Shandong, Taian; 36 $12^{\prime}$ N, 117 ${ }^{\circ} 5^{\prime}$ E; 20 Jul. 2015; Qing-Tao Gong leg.; apple orchard; MT; SCAU 3011647 (SYSBM).

\section{Description}

Male (Figs 6, 8C)

Fully winged; length $1.8 \mathrm{~mm}$. Head black, except mandible testaceous; antenna brown, except scape and pedicel testaceous; mesosoma black; metasoma brown; legs yellow. Antenna filiform; antennomeres in following proportions: $3: 4: 3: 4: 5: 5.5: 5: 6: 6: 10$. Head dull, granulated; frontal line incomplete, absent shortly in front of anterior ocellus; occipital carina complete; $\mathrm{POL}=6 ; \mathrm{OL}=3 ; \mathrm{OOL}=3$; $\mathrm{OPL}=$ $1.5 ; \mathrm{TL}=2$; greatest breadth of lateral ocellus about as long as TL. Mesoscutum and mesoscutellum dull, granulated. Notauli incomplete, reaching approximately $0.5 \times$ length of mesoscutum (Fig. 6C). Metanotum shiny, unsculptured. Metapectal-propodeal complex dull, reticulate rugose, with two complete longitudinal keels on posterior surface; posterior surface with median area unsculptured and

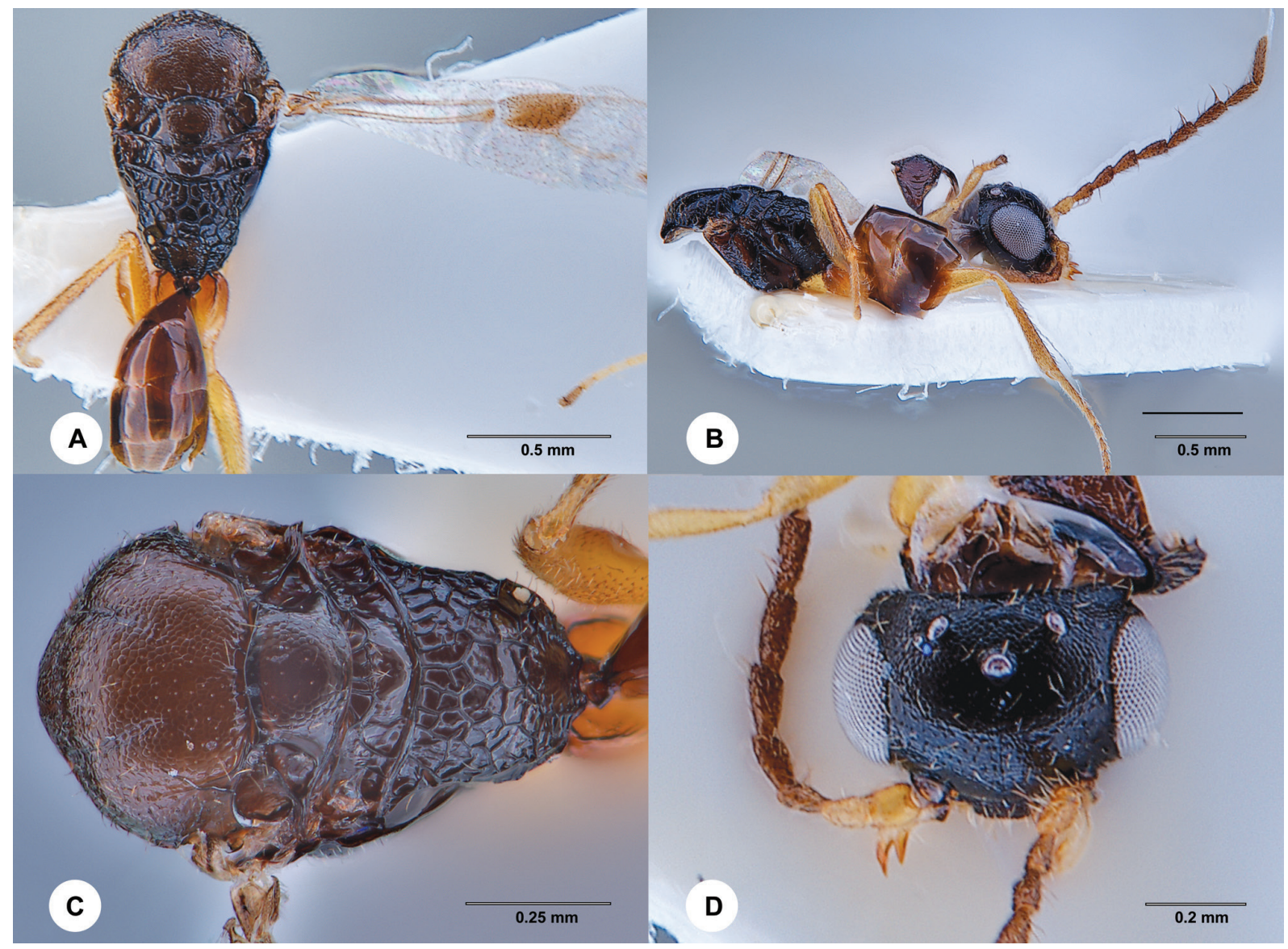

Fig. 6. Aphelopus taianensis Olmi, Ødegaard \& Chen sp. nov., つ̊, holotype (SCAU 3011647). A. Habitus, dorsal view. B. Habitus, lateral view. C. Mesosoma, dorsal view. D. Head, anterodorsal view. 
lateral areas rugose. Fore wing hyaline, without dark transverse bands. Basivolsella (Fig. 8C) very narrow, without distal outer process, with one lateral outer pointed apophysis and two subdistal bristles situated on top of each other. Tibial spurs 1/1/2.

\section{Female}

Unknown.

\section{Remarks}

From the above diagnosis, A. taianensis Olmi, Ødegaard \& Chen sp. nov. is close to A. nepalensis Olmi, 1984. However, in the new species, the basivolsella (Fig. 8C) is very narrow and with one lateral pointed apophysis (very wide and without lateral pointed apophysis in A. nepalensis (Olmi \& Xu 2015: pl. 4k). Following the description of A. taianensis Olmi, Ødegaard \& Chen sp. nov., the key to males of Oriental Aphelopus published by Olmi \& Xu (2015) should be modified by replacing couplet 15 as follows:

15. Notauli reaching approximately $0.65 \times$ length of mesoscutum A. nigriceps Kieffer, 1905

- Notauli reaching approximately $0.5 \times$ length of mesoscutum (Fig. 6C) $15^{\prime}$

15'. Basivolsella very wide, without lateral pointed apophysis, with two subdistal bristles situated on either side of each other (Olmi \& Xu 2015: pl. 4k) A. nepalensis Olmi, 1984

- Basivolsella very narrow, with one lateral pointed apophysis and two subdistal bristles situated on top of each other (Fig. 8C) A. taianensis Olmi, Ødegaard \& Chen sp. nov.

Aphelopus zaifui Olmi, Chen \& Liu sp. nov. urn:1sid:zoobank.org:act:730357C7-2449-42BE-99A6-6DBFFE97DC67

Figs 7, 8D

\section{Diagnosis}

Male with head black, except mandible testaceous; notauli complete (Fig. 7B) or almost complete (Fig. 7F), posteriorly separated; distivolsella in the form of a long straight rod (Fig. 8D); basivolsella long and narrow, with distal apex very widened (Fig. 8D).

\section{Etymology}

The species is named after the late Prof. Zaifu Xu (SCAU), a famous specialist of Chinese Dryinidae.

\section{Material examined}

\section{Holotype}

CHINA • ${ }^{\top}$; Yunnan, Dali, Yunlong County, Tianchi; $25.854158^{\circ}$ N, $99.239927^{\circ}$ E; 2933 m a.s.1., 14-28 Jun. 2020; You-Jing Gong leg.; MT; SCAU 3042343 (SYSBM).

\section{Paratypes}

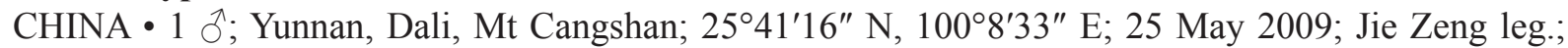

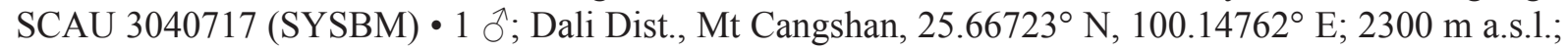
31 May 2020; MT; SCAU 3042339 (SYSBM).

\section{Description}

\section{Male}

Fully winged (Fig. 7A); length $2.0 \mathrm{~mm}$. Head black, except mandible testaceous; antenna brown-black; mesosoma and metasoma black; fore and mid leg yellow, except club of femur brown; hind leg yellow, except part of coxa, club of femur and tibia brown. Antenna filiform, with setae about as long as breadth 


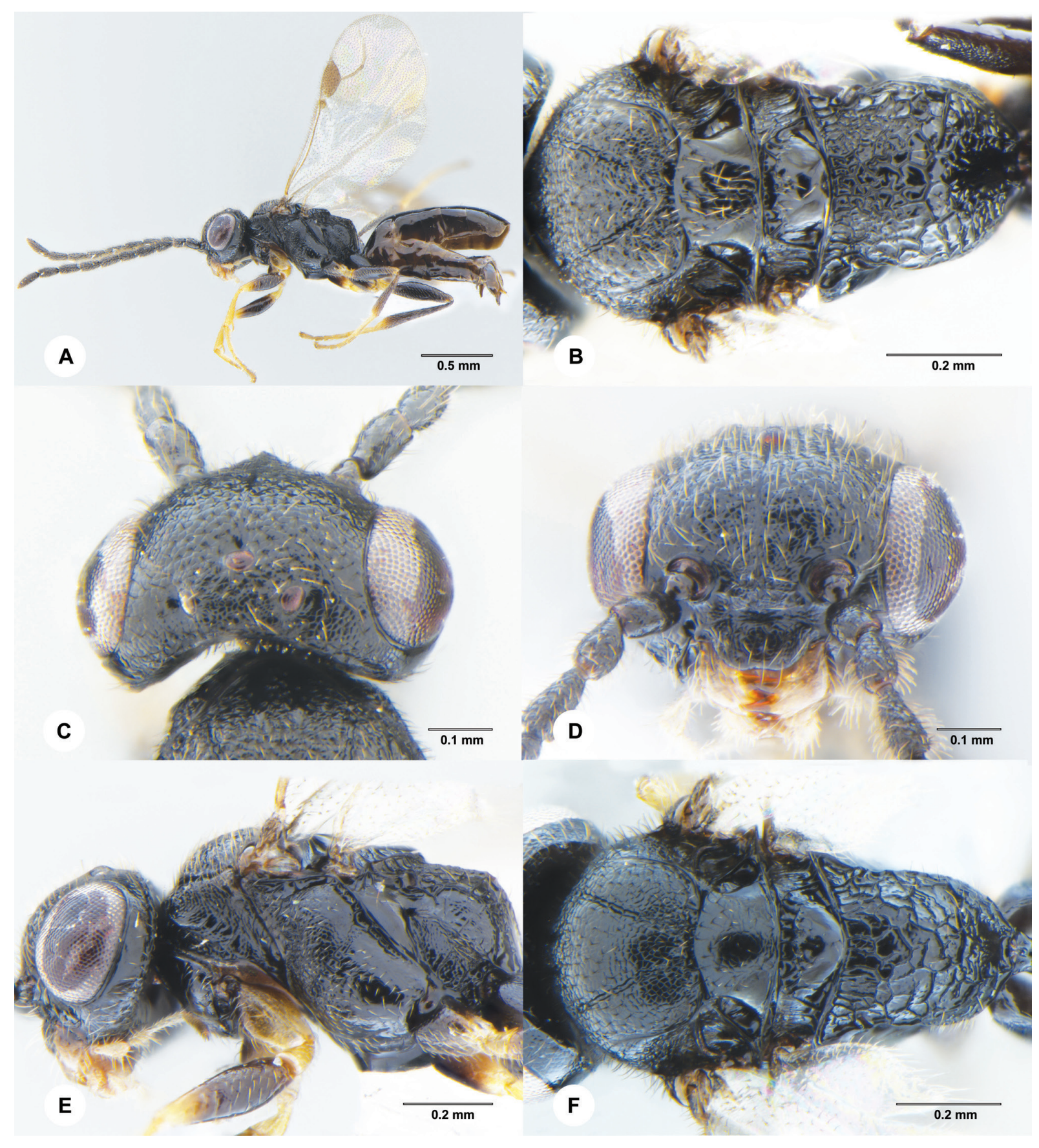

Fig. 7. Aphelopus zaifui Olmi, Chen \& Liu sp. nov. A-E. Holotype, ô (SCAU 3042343). A. Habitus, dorsal view. B. Mesosoma, dorsal view. C. Head, dorsal view. D. Head, frontal view. E. Head and mesosoma, lateral view. F. Paratype, ô (SCAU 3042339), mesosoma, dorsal view. 
of antennomeres; antennomeres in following proportions: 5:5:5:6:6:7:7:7:7:10; length/breadth ratio of ninth antennomere: 7:2. Head (Fig. 7C-D) dull, granulate; frontal line incomplete, present only in anterior half of frons; $\mathrm{POL}=5 ; \mathrm{OL}=3 ; \mathrm{OOL}=3 ; \mathrm{OPL}=2 ; \mathrm{TL}=3$; greatest breadth of lateral ocelli about as long as OPL; occipital carina complete. Mesoscutum (Figs 7B, F) dull, granulate. Notauli complete (Fig. 7B) or nearly complete (Fig. 7F), posteriorly separated; minimum distance between notauli slightly shorter than POL (4:5). Mesoscutellum shiny, very slightly granulate. Mesopleuron and metapleuron shiny, unsculptured. Metanotum shiny, unsculptured. Metapectal-propodeal disc reticulate rugose; propodeal declivity with two longitudinal keels and median area shiny, unsculptured. Fore wing hyaline, without
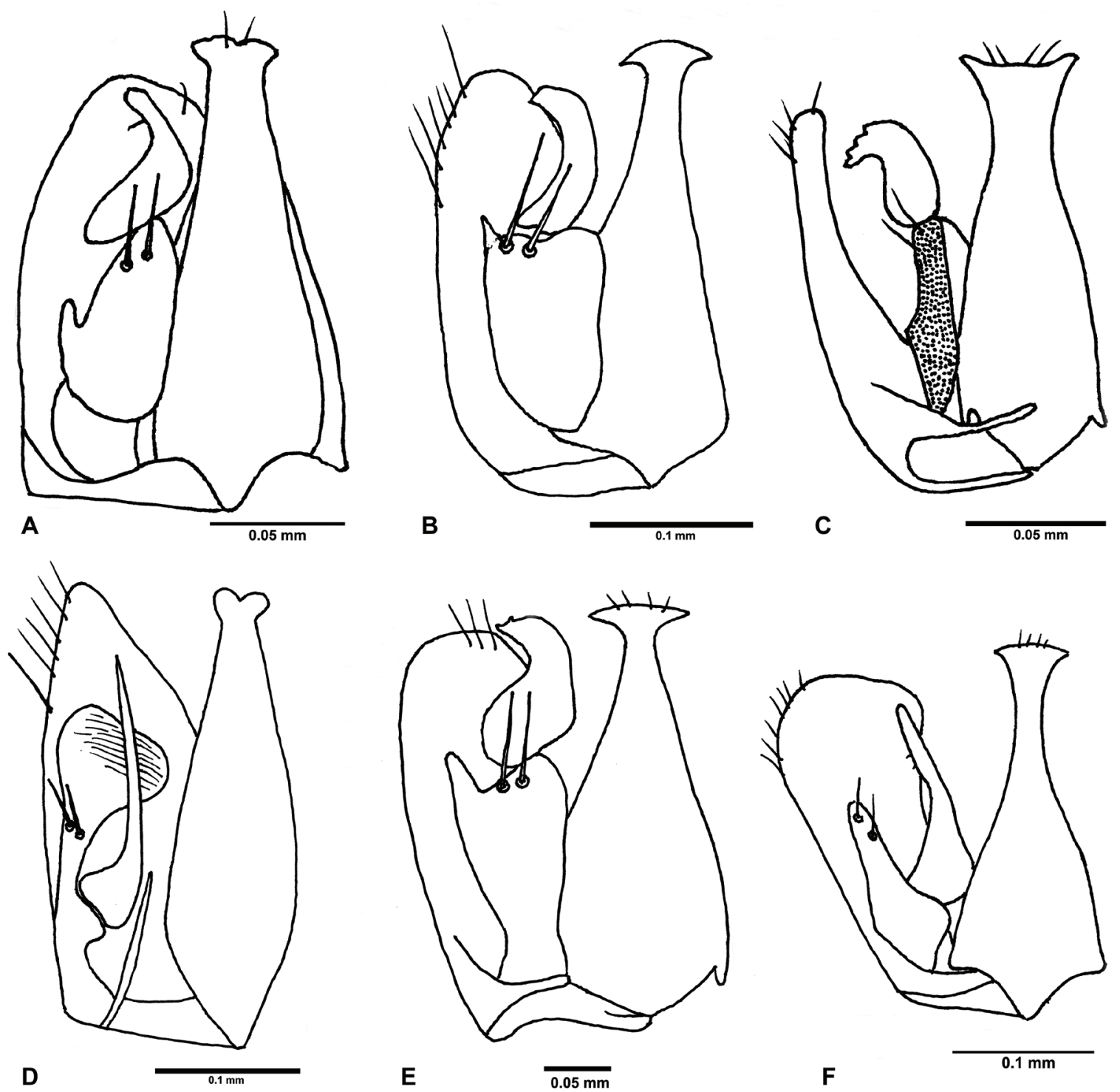

Fig. 8. Male genitalia: A. Aphelopus incognitus Chen, Olmi \& Guglielmino sp. nov., $\widehat{\partial}$, holotype. B. Aphelopus maculiala Olmi, Chen \& Ødegaard sp. nov., ô, holotype. C. Aphelopus taianensis Olmi, Ødegaard \& Chen sp. nov., §̂, holotype. D. Aphelopus zaifui Olmi, Chen \& Liu sp. nov., §̂, paratype. E. Aphelopus spadiceus Xu \& He, Ô from China, Sichuan, Wolong. F. Aphelopus serratus Richards, 1939, ठ̊ from Leicester (England, UK). Right half removed. 
dark transverse bands. Distivolsella in form of long straight rod (Fig. 8D); basivolsella long and narrow, with two medial bristles and distal apex very widened (Fig. 8D); distal apex of aedeagus not tridentate (Fig. 8D). Tibial spurs $1 / 1 / 2$.

\section{Female}

Unknown.

\section{Remarks}

The distivolsella in the form of a long straight rod indicates that the new species is different from all known Aphelopus species, except A. serratus Richards, 1939, from the Palaearctic region. However, in A. zaifui Olmi, Chen \& Liu sp. nov. the basivolsella has a widened apex (Fig. 8D), whereas in A. serratus it has a slender apex (Fig. 8F). Following the description of A. zaifui Olmi, Chen \& Liu sp. nov., the key to males of Oriental Aphelopus published by Xu et al. (2013) should be modified by replacing couplet 1 as follows:

1. Distivolsella in the form of a long straight rod (Fig. 8D); basivolsella long and narrow, with distal apex very widened (Fig. 8D) A. zaifui Olmi, Chen \& Liu sp. nov.

- Distivolsella and basivolsella with different shape (Fig. 8A-B) 1

1'. Mesosoma and metasoma totally testaceous, except petiole black A. borneanus Olmi, 1984

- Mesosoma and metasoma partly or totally black or brown 2

\section{Other examined material from China}

Aphelopus albiclypeus Xu, He \& Olmi, 1999

Fig. 9

Aphelopus albiclypeus Xu, He \& Olmi, 1999: 90.

Aphelopus albiclypeus - Xu et al. 2013: 17.

\section{Material examined}

CHINA -1 đ̇; Yunnan, Maguan Town, Bazhai County, near dam; $23.021373^{\circ} \mathrm{N}, 104.06459^{\circ} \mathrm{E}$; 1749 m a.s.l.; Jun. 2017; Li Ma leg.; forest; MT; SCAU 3011737 (SYSBM).

\section{Distribution}

China, Laos, Thailand, Vietnam (Xu et al. 2013).

Aphelopus albifacialis Xu \& He, 1997

Fig. 10

Aphelopus albifacialis Xu \& He in Xu et al., 1997: 7.

Aphelopus albifacialis - Xu et al. 2013: 19.

\section{Material examined}

CHINA • 1 q; Yunnan, Xishuangbanna, Menghai, Bulangshan Village, Area D, near road; $21^{\circ} 44.745^{\prime} \mathrm{N}$, 100²6.07' E; 1621 m a.s.1., 20 Jun.-20 Jul. 2018; Li Ma leg.; MT; SCAU 3011667 (SYSBM) • 1 ㅇ; Guangdong, Shenzhen, Xianhu Botanical Garden; 22.580382 ${ }^{\circ}$ N, $114.172781^{\circ}$ E; 31 Mar.-30 Apr. 2020; Long-Long Chen leg.; LSX447, MT-GD28; SCAU 3048845 (SYSBM). 


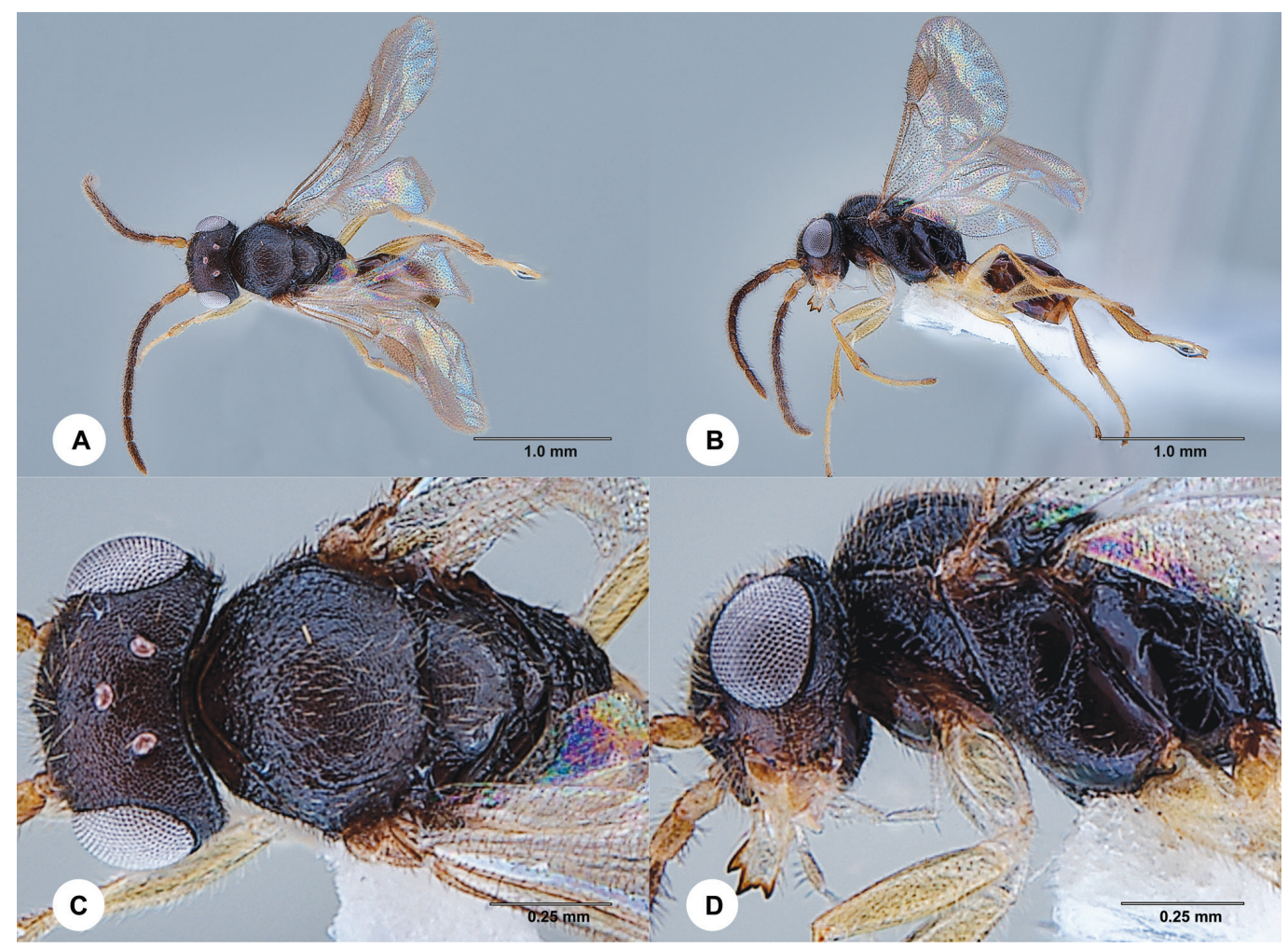

Fig. 9. Aphelopus albiclypeus Xu, He \& Olmi, 1999, ô (SCAU 3011737). A. Habitus, dorsal view. B. Habitus, lateral view. C. Head and mesosoma, dorsal view. D. Head and mesosoma, lateral view.

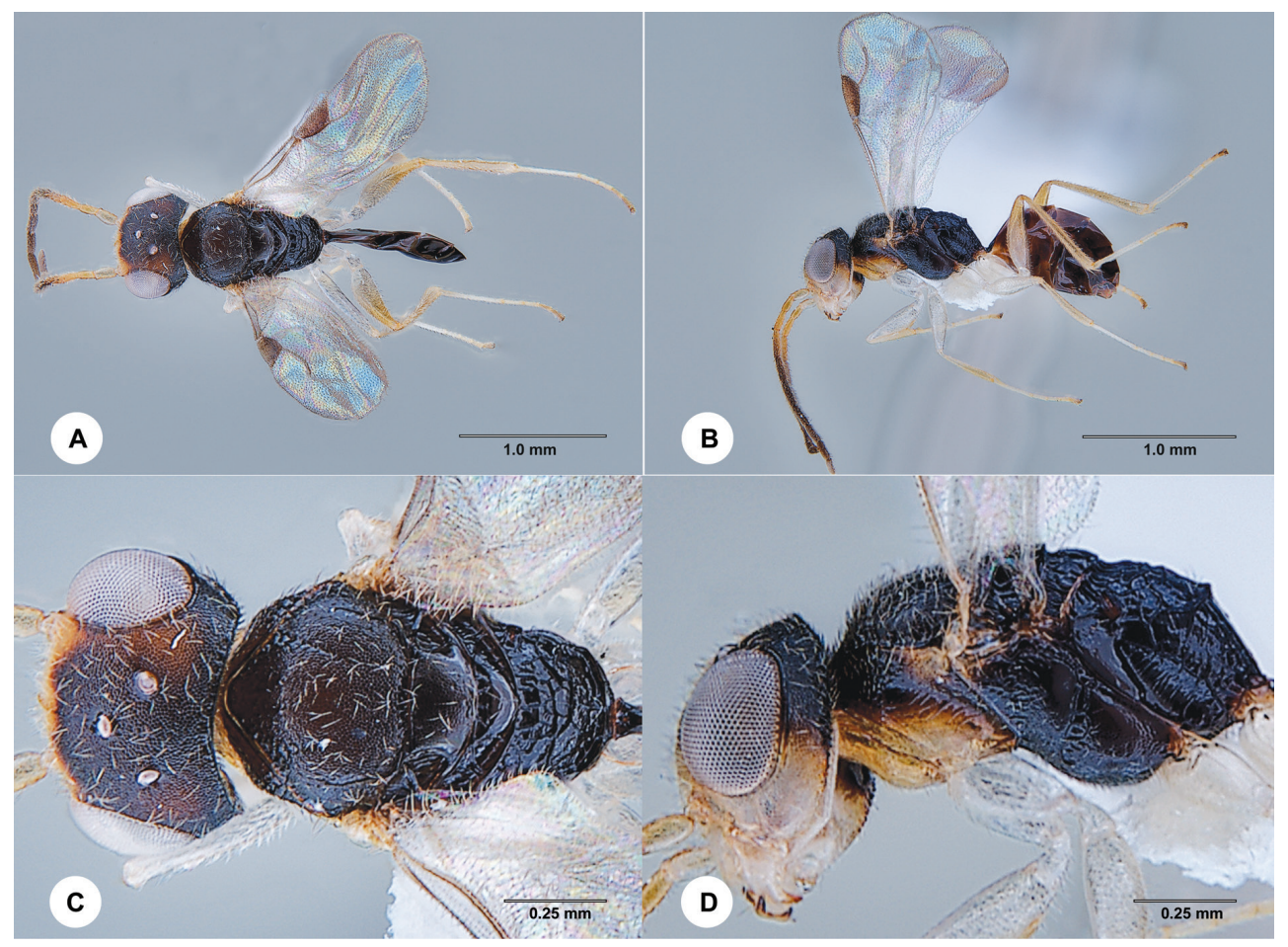

Fig. 10. Aphelopus albifacialis Xu \& He, 1997, ô (SCAU 3011667). A. Habitus, dorsal view. B. Habitus, lateral view. C. Head and mesosoma, dorsal view. D. Head and mesosoma, lateral view. 


\section{Distribution}

China (Xu et al. 2013).

Aphelopus maculiceps Bergman, 1957

Fig. 11

Aphelopus maculiceps Bergman, 1957: 9.

Aphelopus maculiceps - Xu et al. 2013: 23.

\section{Material examined}

CHINA • 1 \%; Sichuan, Chengdu, Longquanyi District, Baihe Town, Changsong Village; $30^{\circ} 31^{\prime} 17^{\prime \prime} \mathrm{N}$, $104^{\circ} 17^{\prime} 0^{\prime \prime}$ E; 8 Oct. 2012; MT; SCAU 3011637 (SYSBM).

\section{Distribution}

China, India, Indonesia, Vietnam (Xu et al. 2013).

Aphelopus malayanus Olmi, 1984

Fig. 12

Aphelopus malayanus Olmi, 1984: 66.

Aphelopus malayanus - Xu et al. 2013: 26.

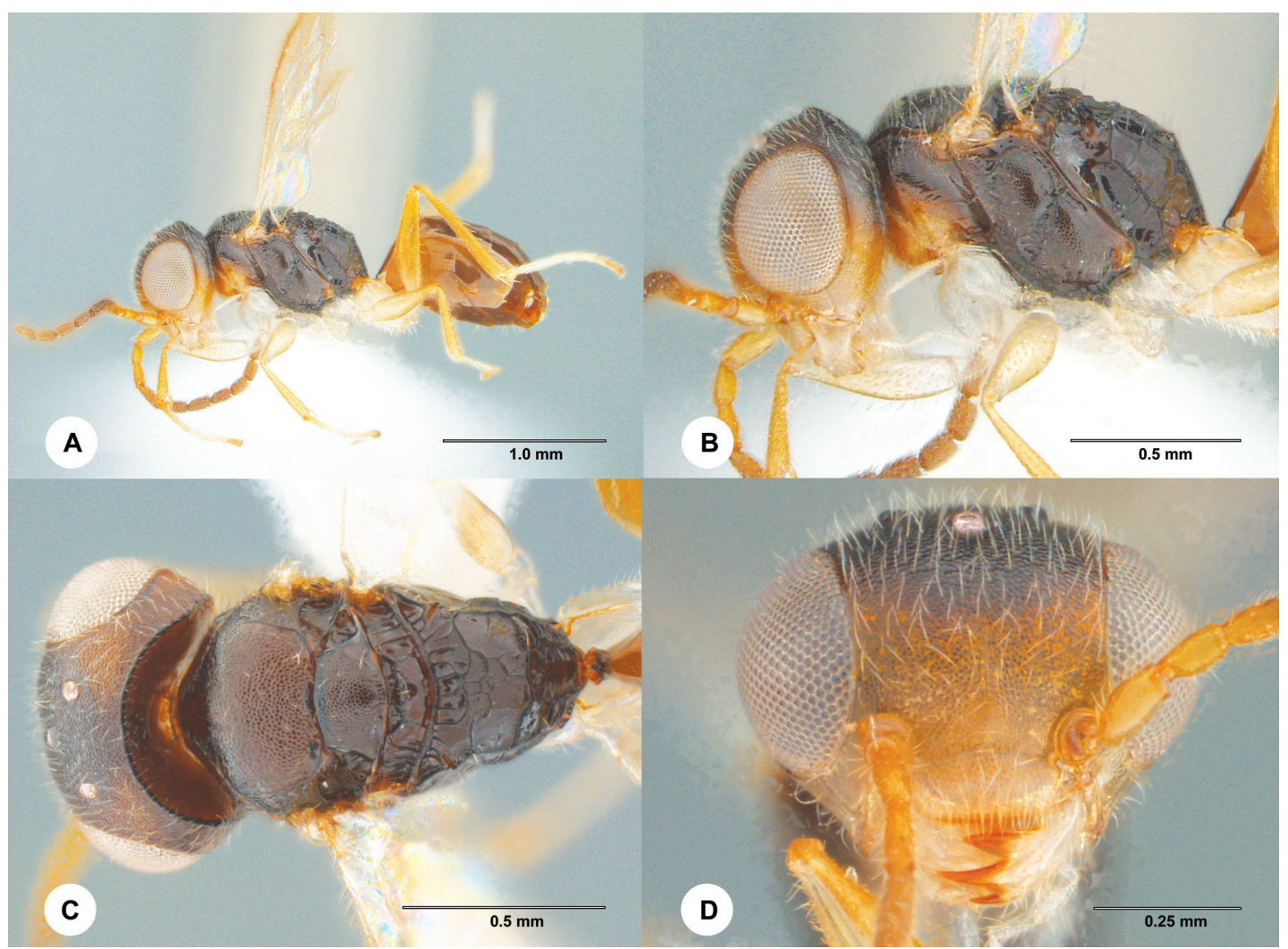

Fig. 11. Aphelopus maculiceps Bergman, 1957, ð̊ (SCAU 3011637). A. Habitus, lateral view. B. Head and mesosoma, lateral view. C. Head and mesosoma, dorsal view. D. Head, frontal view. 


\section{Material examined}

CHINA • 1 q; Guangdong, Guangzhou University Town; 232'925" N, 113²1'25" E; 20 Jan.-17 Feb. 2019; Hua-Yan Chen leg.; wetland; MT; SCAU 3040507 (SYSBM).

\section{Distribution}

Brunei, China, India, Indonesia, Laos, Malaysia, Nepal, Philippines, Thailand (Xu et al. 2013), South Korea (Kim \& Lee 2016).

Aphelopus mangshanensis Xu, Olmi, Guglielmino \& Chen, 2011

Fig. 13

Aphelopus mangshanensis Xu, Olmi, Guglielmino \& Chen, 2011: 243.

Aphelopus mangshanensis - Xu et al. 2013: 27.

\section{Material examined}

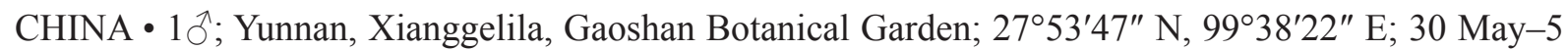
Aug. 2018; Jie Zeng leg.; MT; SCAU 3011672 (SYSBM).

\section{Distribution}

China (Xu et al. 2013).

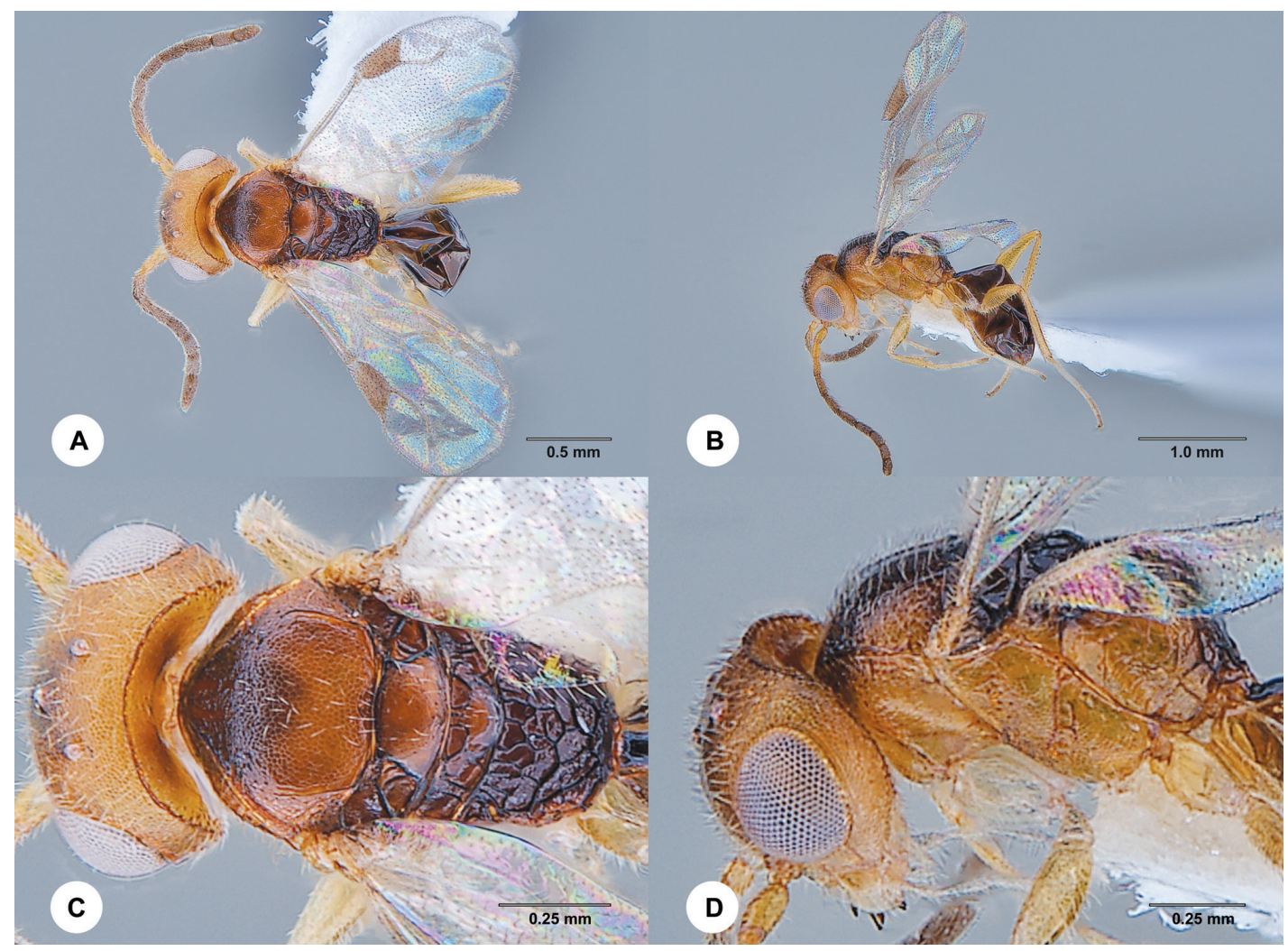

Fig. 12. Aphelopus malayanus Olmi, 1984, ô (SCAU 3040507). A. Habitus, dorsal view. B. Habitus, lateral view. C. Head and mesosoma, dorsal view. D. Head and mesosoma, lateral view. 


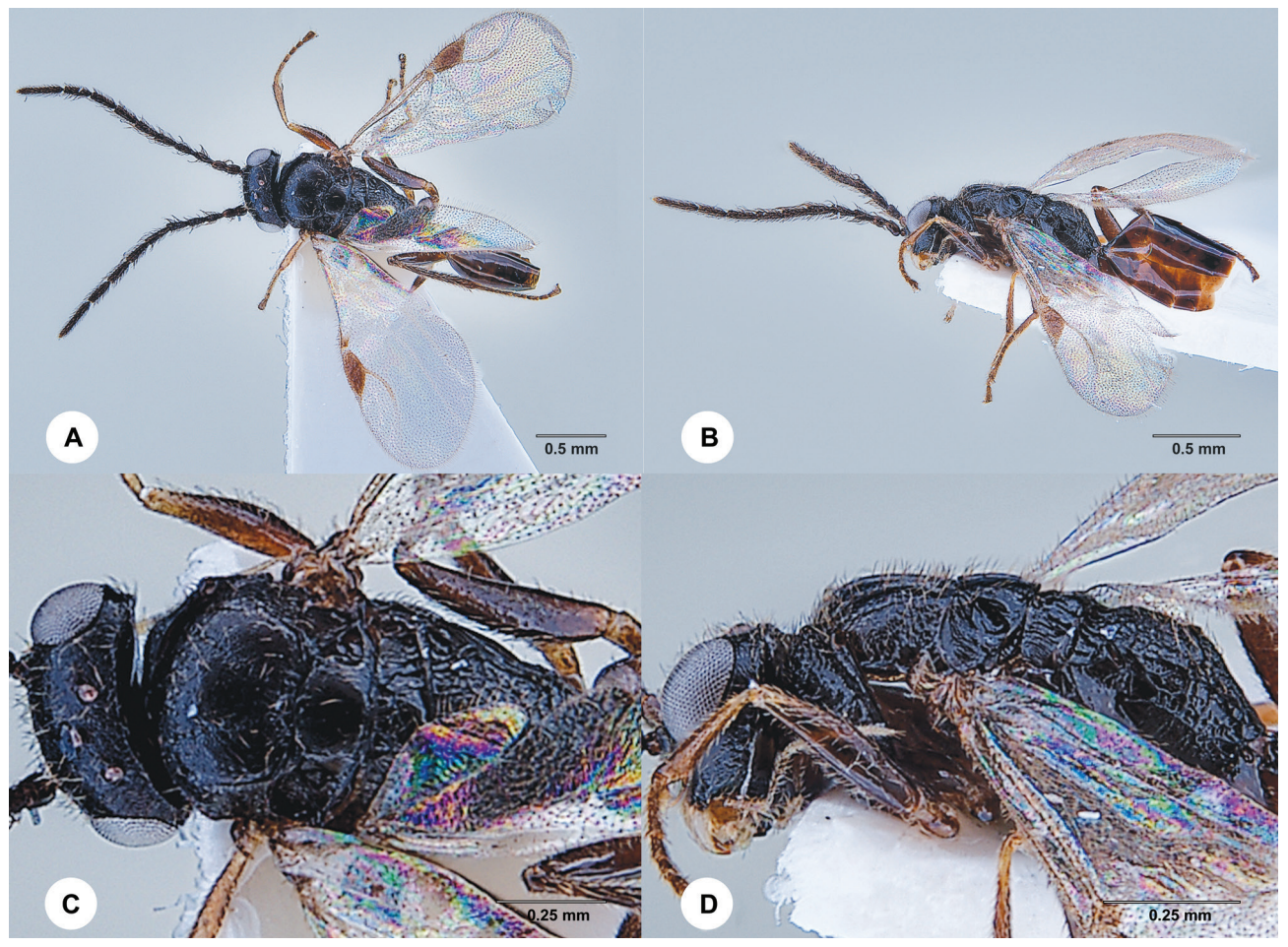

Fig. 13. Aphelopus mangshanensis Xu, Olmi, Guglielmino \& Chen, 2011, ô (SCAU 3011672). A. Habitus, dorsal view. B. Habitus, lateral view. C. Head and mesosoma, dorsal view. D. Head and mesosoma, lateral view.

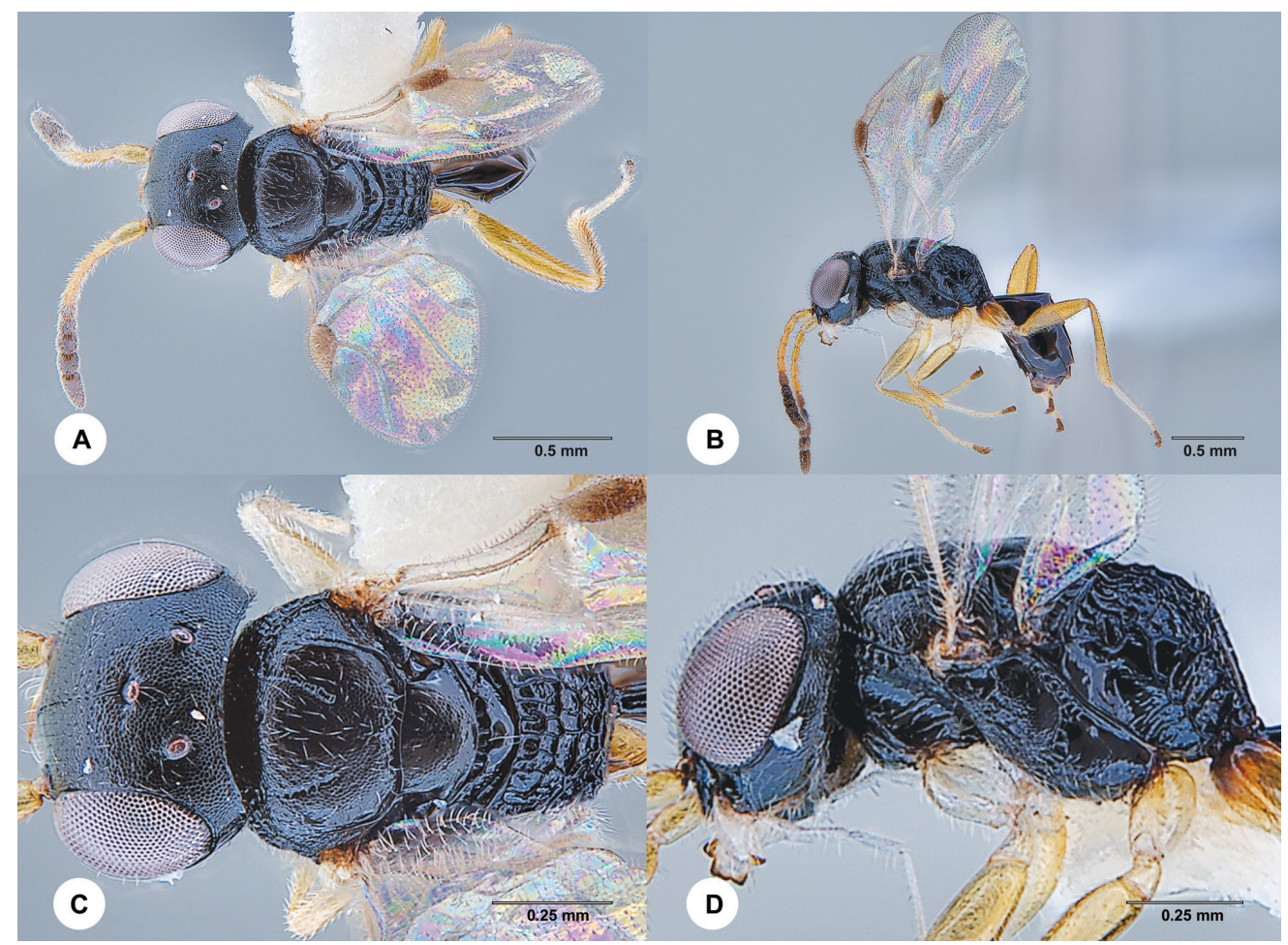

Fig. 14. Aphelopus niger Xu \& He, 1999, ㅇ (SCAU 3040438). A. Habitus, dorsal view. B. Habitus, lateral view. C. Head and mesosoma, dorsal view. D. Head and mesosoma, lateral view. 


\section{Aphelopus niger Xu \& He, 1999}

Fig. 14

Aphelopus niger Xu \& He, 1999: 2.

Aphelopus niger - Xu et al. 2013: 30.

\section{Material examined}

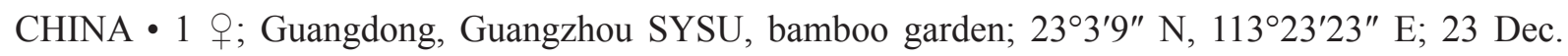
2018-20 Jan. 2019; Hua-Yan Chen leg.; MT; SCAU 3040438 (SYSBM).

\section{Distribution}

China (Xu et al. 2013).

\section{Aphelopus nivealis Mita \& Olmi, 2014}

Fig. 15

Aphelopus nivealis Mita \& Olmi, 2014: 93.

Aphelopus nivealis - Olmi \& Xu 2015: 25.

\section{Material examined}

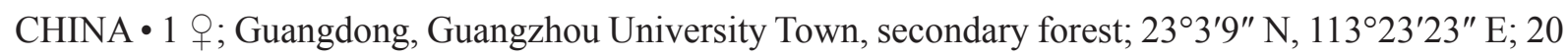
Jan.-17 Feb. 2019; Hua-Yan Chen leg.; MT; SCAU 3040508 (SYSBM) • 1 क; Guangdong, Shenzhen, Mt Tanglangshan; 22.570411639 $9^{\circ}$, $113.99317344^{\circ}$ E; LSX498, 7-30 May 2020; Long-Long Chen leg.; MT-GD7; SCAU 3049357 (SYSBM).

\section{Distribution}

Japan (Honshu), China (Guangdong) (new record).

\section{Remarks}

Aphelopus nivealis Mita \& Olmi, 2014 was originally described from the Eastern Palaearctic region (Honshu, Japan) (see Olmi \& Xu 2015). In this species there are no notauli. One of the two specimens above (from Guangdong, $22.570411639^{\circ} \mathrm{N}, 113.99317344^{\circ} \mathrm{E}$ ) matches completely with the description of $A$. nivealis, including the body colour and the absence of notauli (Fig. 15A-B). On the contrary, the

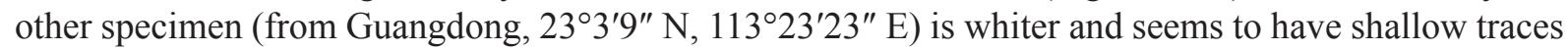
of notauli reaching about $0.5 \times$ length of mesoscutum (Fig. 15C-D). The genetic distance between the two specimens is only $0.6 \%$, suggesting that the variations are just intraspecific. These records indicate that $A$. nivealis is present both in the Eastern Palaearctic and the Oriental regions.

\section{Aphelopus penanganus Olmi, 1984}

Fig. 16

Aphelopus penanganus Olmi, 1984: 68.

Aphelopus penanganus - Xu et al. 2013: 33. — Barthélémy \& Olmi 2019: 533.

\section{Material examined}

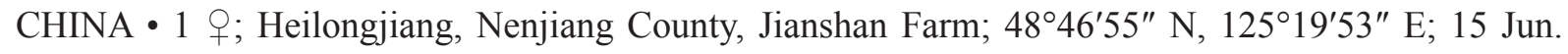
2015; MT; SCAU 3011639 (SYSBM). 


\section{Distribution}

China (Fujian, Hainan, Heilongjiang, Henan, Hong Kong, Ningxia, Taiwan, Yunnan, Zhejiang), India (Tamil Nadu), Indonesia (Sulawesi), Malaysia (Malaya, Sabah), Thailand (Chaiyaphum, Chiang Mai, Trang) (Xu et al. 2013; Barthélémy \& Olmi 2019).

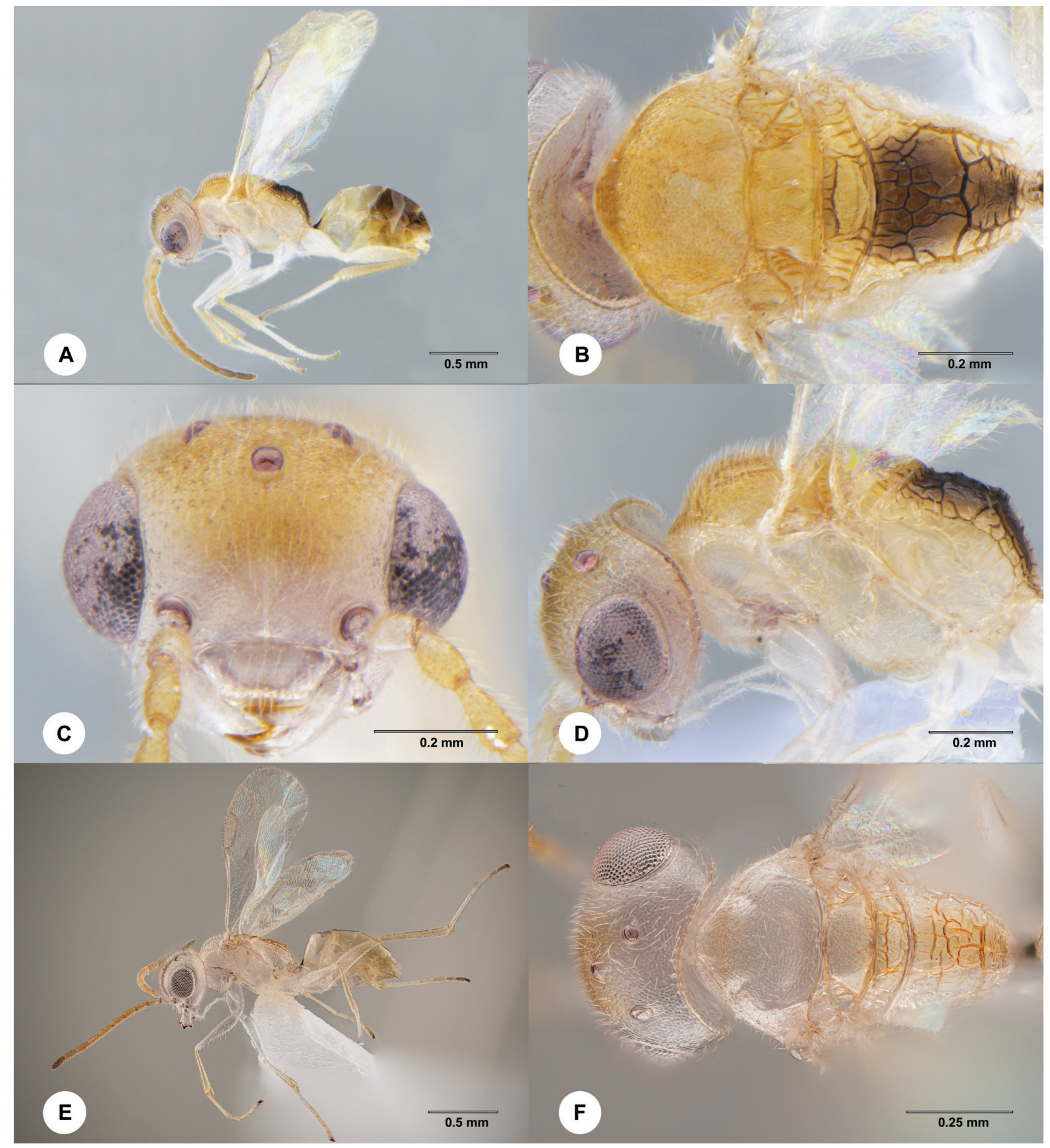

Fig. 15. Aphelopus nivealis Mita \& Olmi, 2014. A-B. \& (SCAU 3049357) A. Habitus, lateral view. B. Mesosoma, dorsal view. C-D. 9 (SCAU 3040508) C. Habitus, lateral view. D. Head and mesosoma, dorsal view. 


\section{Remarks}

The presence of $A$. penanganus in China, Heilongjiang Province, indicates that this species is present both in the Eastern Palaearctic and Oriental regions.

\section{Aphelopus prolatus Mita \& Olmi, 2014}

Fig. 17

Aphelopus prolatus Mita \& Olmi, 2014: 91.

Aphelopus prolatus - Olmi \& Xu 2015: 27.

\section{Material examined}

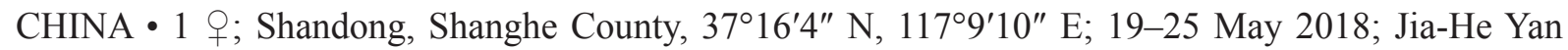
leg.; MT3; SCAU 3040426 (SYSBM) • 1 क ; same locality as for preceding; 26 May-1 Jun. 2018; MT4; SCAU 3011685 (SYSBM).

\section{Distribution}

Japan, Sweden (Olmi \& Xu 2015), South Korea (Kim \& Lee 2016), China (new record).

\section{Aphelopus sabahnus Olmi, 1991}

\section{Fig. 18}

Aphelopus sabahnus Olmi, 1991: 113.

Aphelopus sabahnus - Xu et al. 2013: 35.

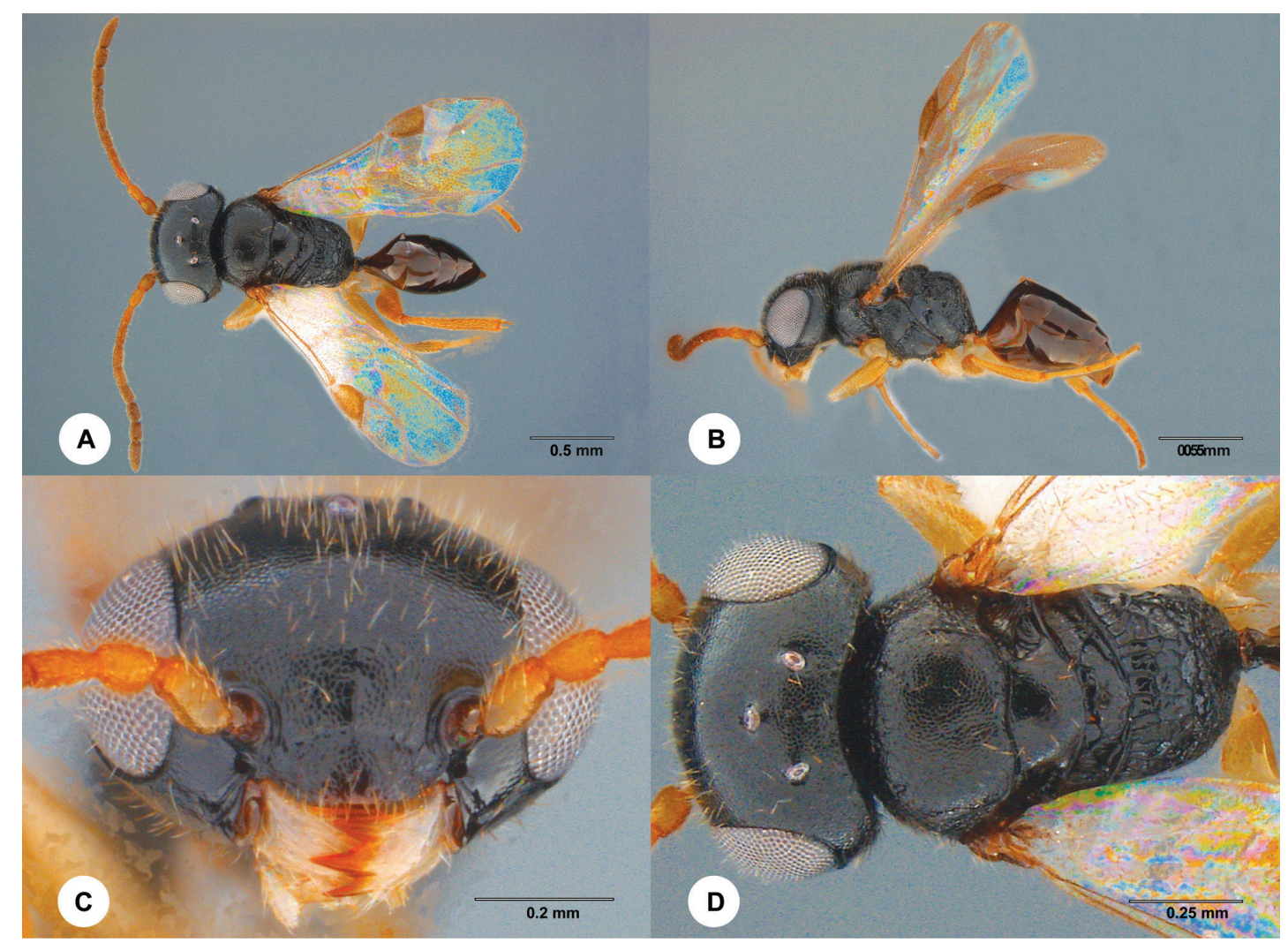

Fig. 16. Aphelopus penanganus Olmi, 1984, q (SCAU 3011639). A. Habitus, dorsal view. B. Habitus, lateral view. C. Head, frontal view. D. Head and mesosoma, dorsal view. 


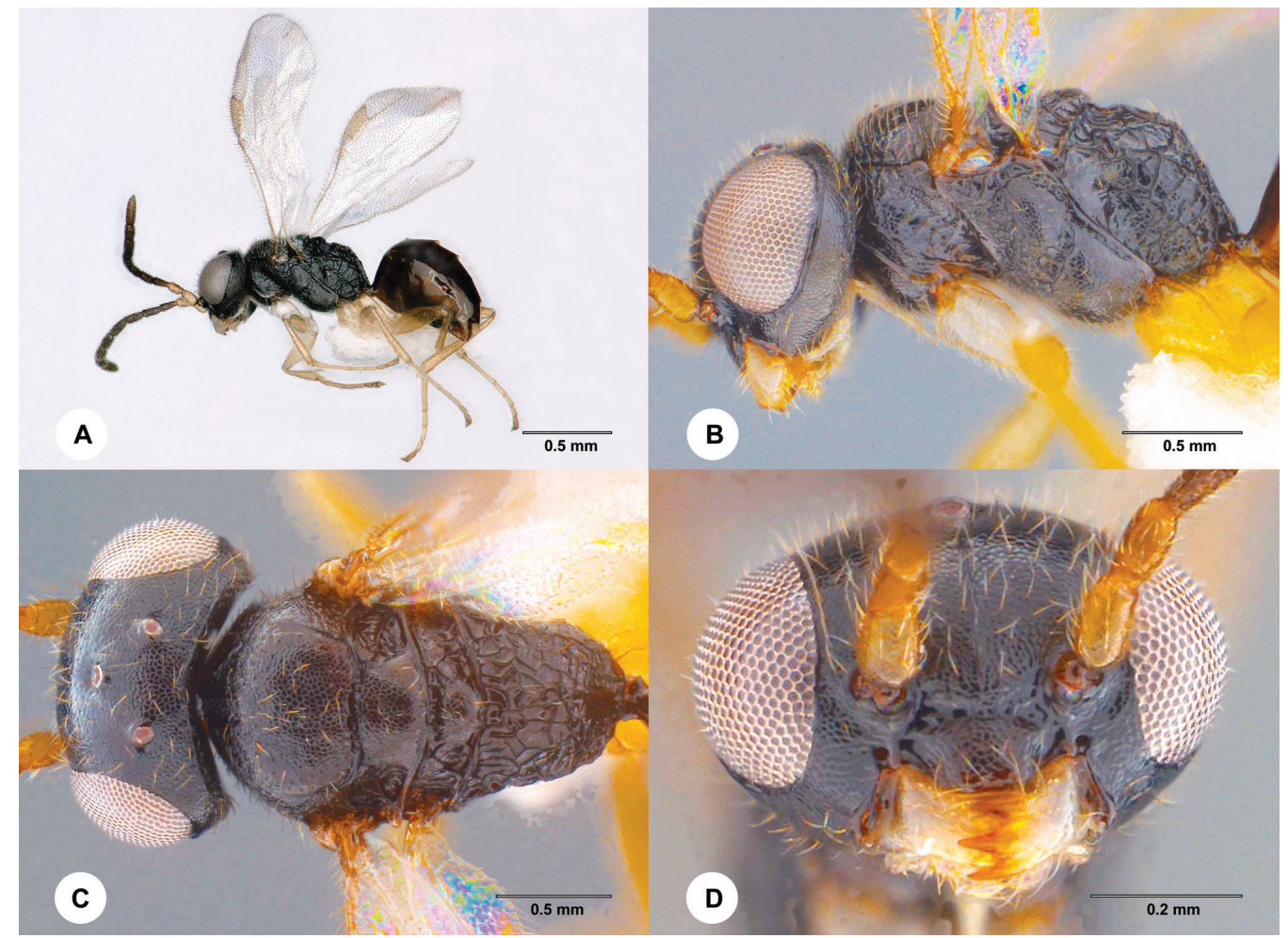

Fig. 17. Aphelopus prolatus Mita \& Olmi, 2014, $q$ (SCAU 3011685). A. Habitus, dorsal view. B. Habitus, lateral view. C. Head and mesosoma, dorsal view. D. Head, frontal view.

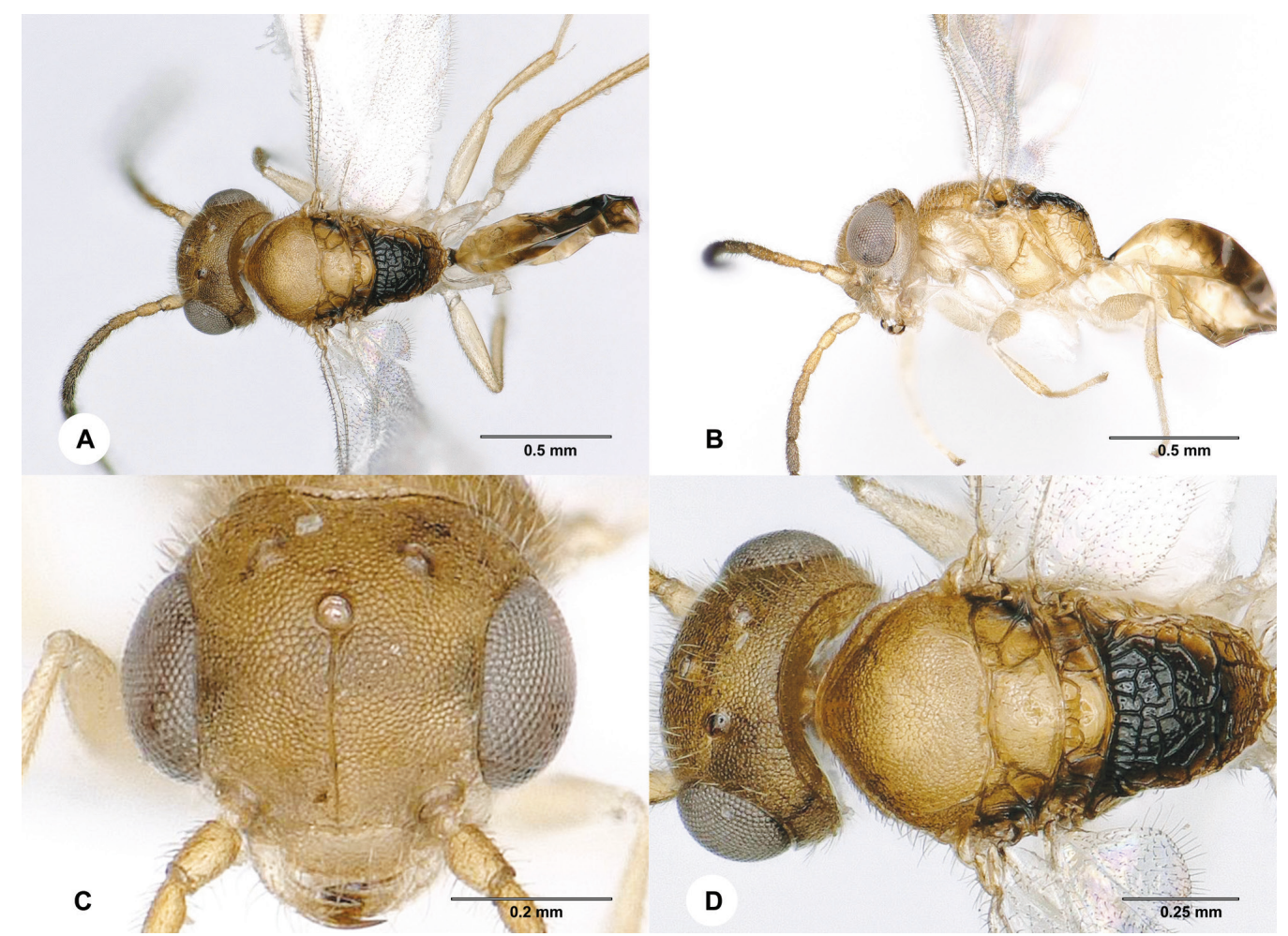

Fig. 18. Aphelopus sabahnus Olmi, 1991, q (SCAU 3011690). A. Habitus, dorsal view. B. Habitus, lateral view. C. Head, frontal view. D. Head and mesosoma, dorsal view. 


\section{Material examined}

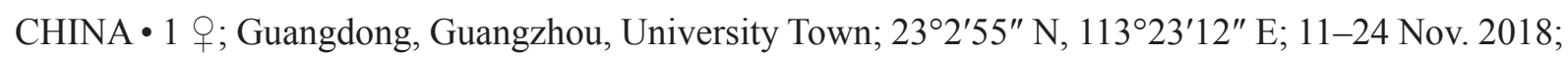
Hua-Yan Chen leg.; forest, MT; SCAU 3011690 (SYSBM).

\section{Distribution}

China, Malaysia (Xu et al. 2013).

\section{Aphelopus spadiceus Xu \& He, 1997}

Figs 8E, 19

Aphelopus spadiceus Xu \& He in Xu et al., 1997: 8.

Aphelopus spadiceus - Xu et al. 2013: 36.

\section{Material examined}

CHINA • 1 ○; Yunnan, Lanping Dist., Mt Lasha; $26.324010^{\circ}$ N, 99.275624 E; 2500 m a.s.1., 20-30 Jul. 2018; Jin-Ku Li leg.; farm land, MT; SCAU 3040510 (SYSBM).

\section{Distribution}

Brunei, China, Thailand (Olmi \& Xu 2015), South Korea (Kim \& Lee 2016).

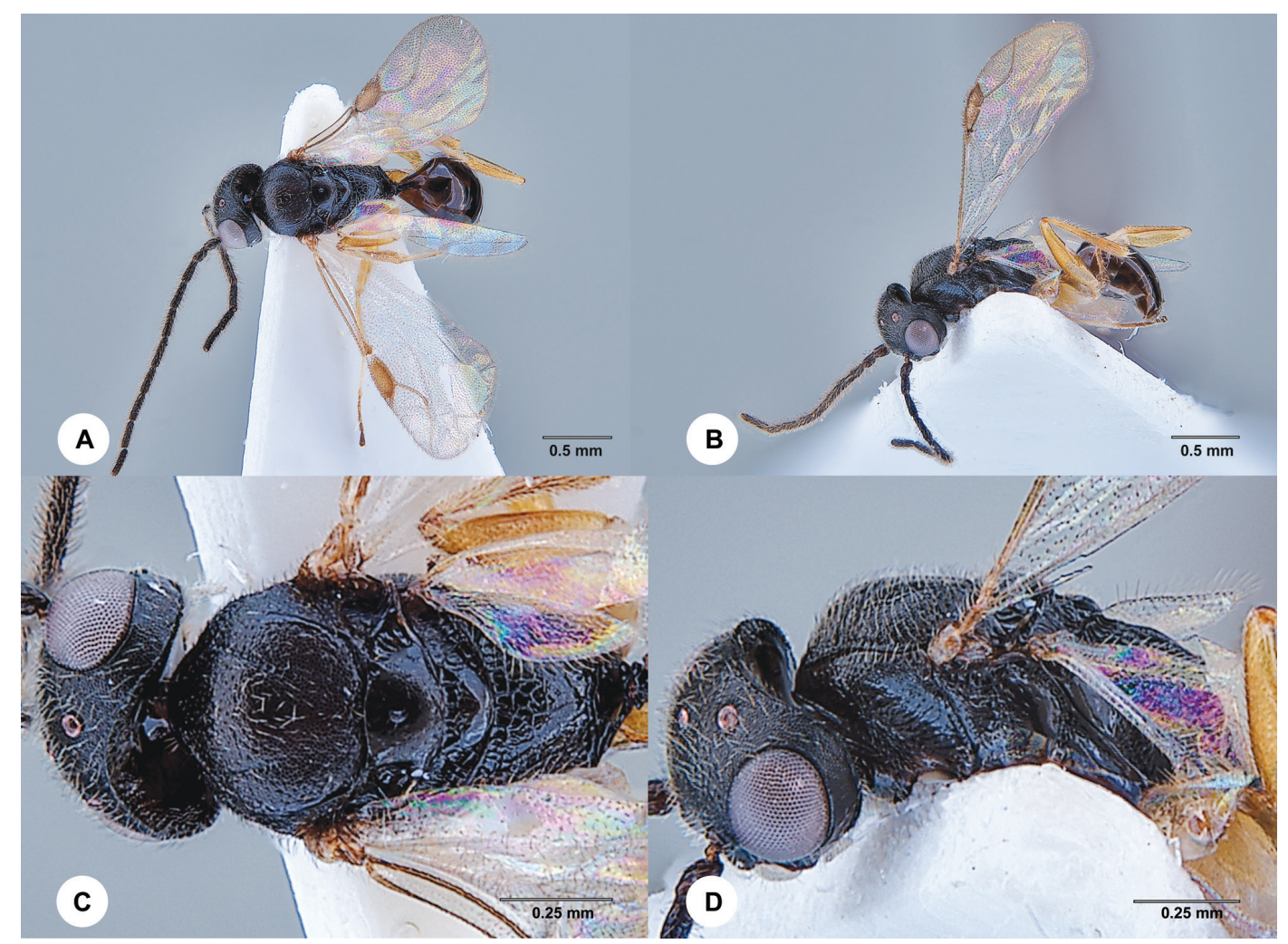

Fig. 19. Aphelopus spadiceus Xu \& He, 1997, ô (SCAU 3040510). A. Habitus, dorsal view. B. Habitus, lateral view. C. Head and mesosoma, dorsal view. D. Head and mesosoma, lateral view. 
Aphelopus wushensis Olmi, 2010

Fig. 20

Aphelopus wushensis Olmi, 2010: 12.

Aphelopus wushensis - Xu et al. 2013: 40.

\section{Material examined}

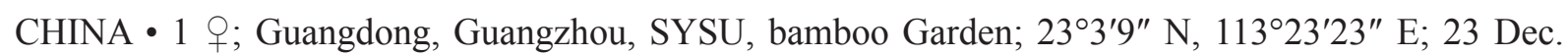
2018-20 Jan. 2019; Hua-Yan Chen leg.; MT; SCAU 3040509 (SYSBM) • 1 क; Yunnan, Xishuangbanna, Menghai, Bulangshan Village, Area D, near road; $21^{\circ} 44.745^{\prime} \mathrm{N}, 100^{\circ} 26.07^{\prime} \mathrm{E} ; 1621 \mathrm{~m}$ a.s.1., 28 Jun-19 Jul. 2019; Li Ma leg.; MT; SCAU 3044042 (SYSBM).

\section{Distribution}

China, Philippines (Xu et al. 2013).

Aphelopus zhaoi Xu, He \& Olmi, 1998

Fig. 21

Aphelopus zhaoi Xu, He \& Olmi, 1998: 22.

Aphelopus zhaoi-Xu et al. 2013: 42.

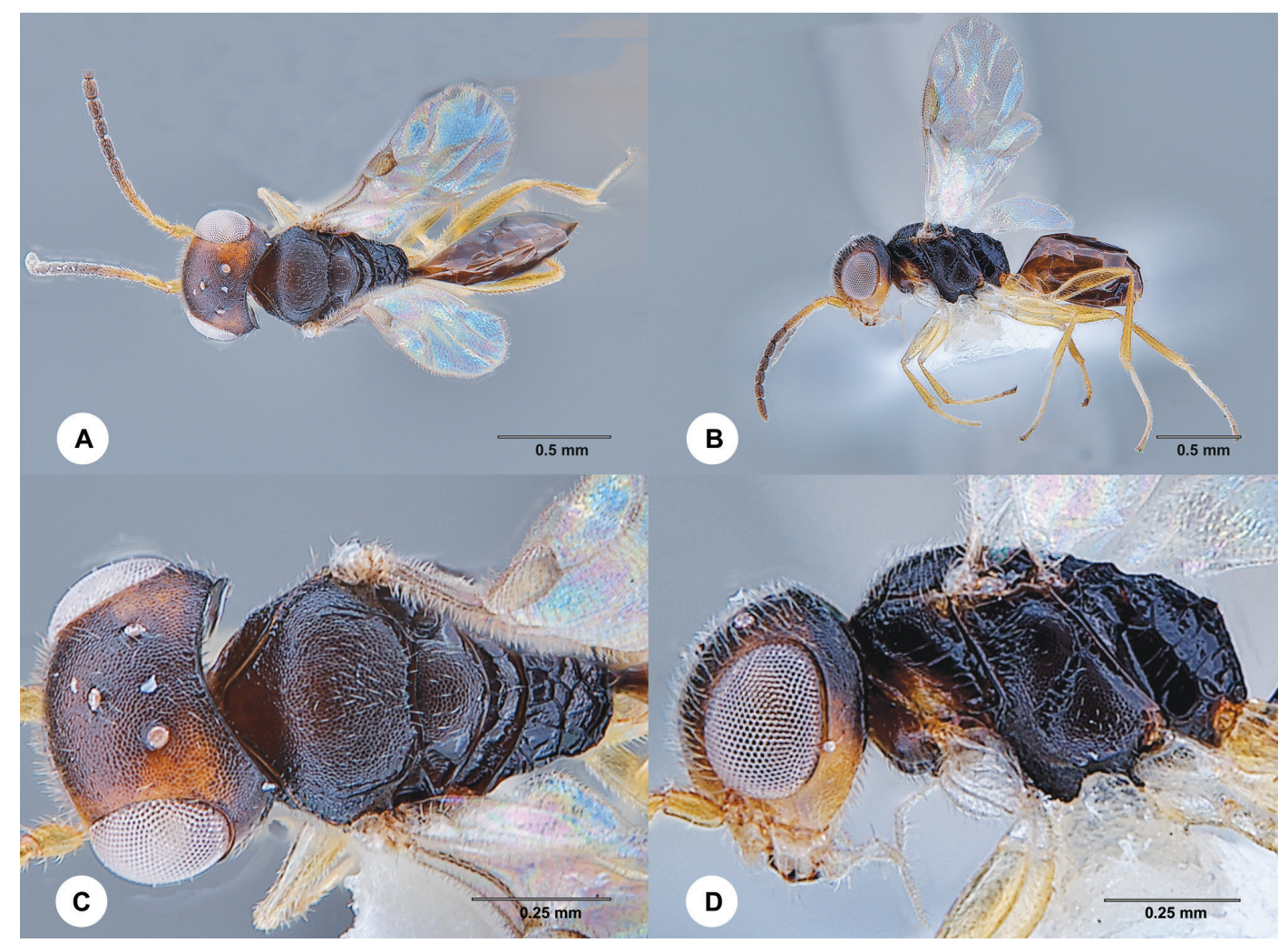

Fig. 20. Aphelopus wushensis Olmi, 2010, q (SCAU 3040509). A. Habitus, dorsal view. B. Habitus, lateral view. C. Head and mesosoma, dorsal view. D. Head and mesosoma, lateral view. 


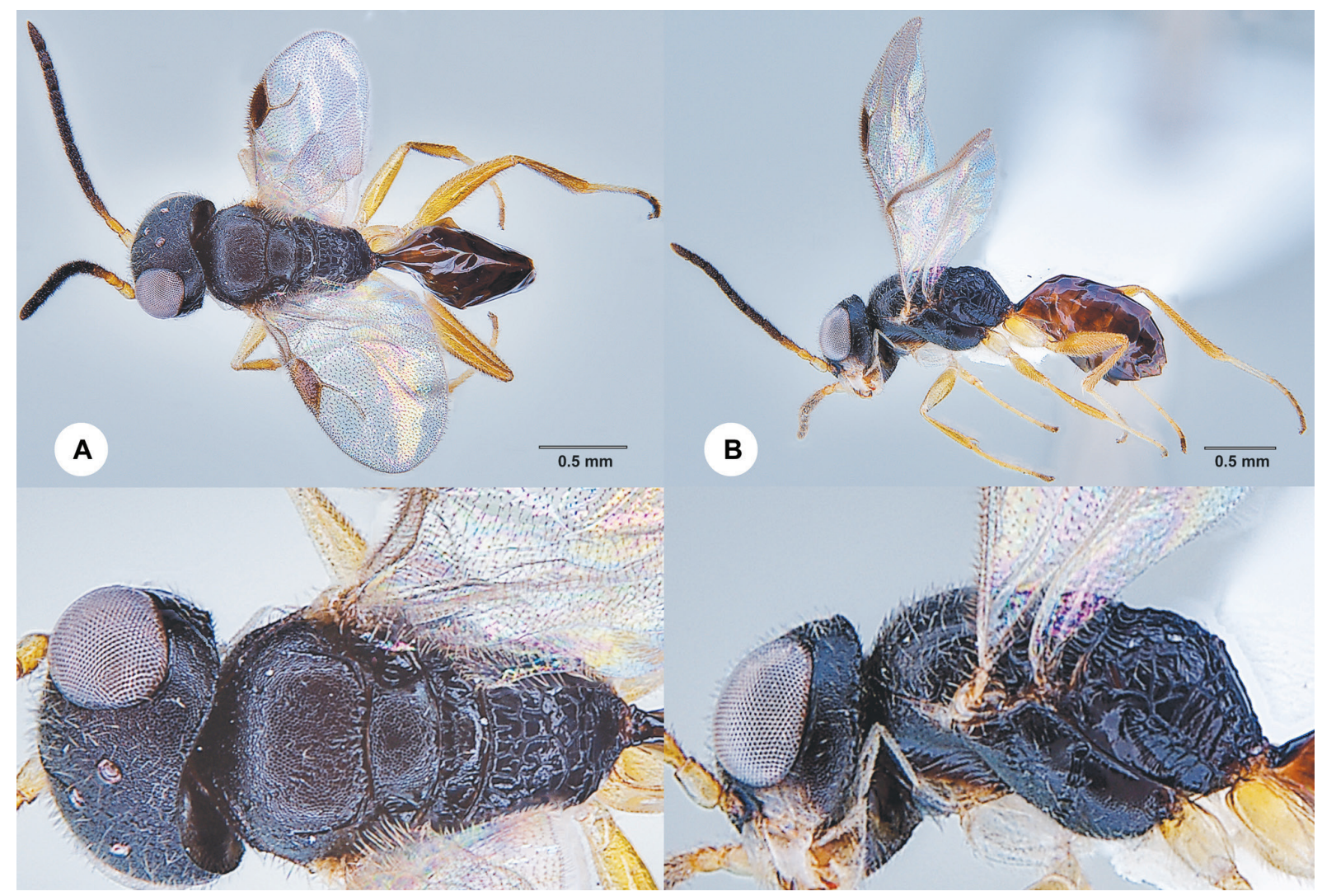

Fig. 21. Aphelopus zhaoi Xu, He \& Olmi, 1998, q (SCAU 3011659). A. Habitus, dorsal view. B. Habitus, lateral view. C. Head and mesosoma, dorsal view. D. Head and mesosoma, lateral view.

\section{Material examined}

CHINA - 1 O; Yunnan, Xishuangbanna, Menghai, Bulangshan Village, Area A, grass; $21^{\circ} 45.037^{\prime} \mathrm{N}$, 100²6.715' E; 1683 m a.s.1.; 17 May-21 Jun. 2018; Li Ma leg.; MT; SCAU 3011659 (SYSBM).

\section{Distribution}

China (Xu et al. 2013).

\section{Other material from northern Europe examined for comparison}

\section{Aphelopus atratus (Dalman, 1823)}

Dryinus (Aphelopus) atratus Dalman, 1823: 15.

Aphelopus atratus (Dalman) - Olmi \& Xu 2015: 14.

\section{Material examined}

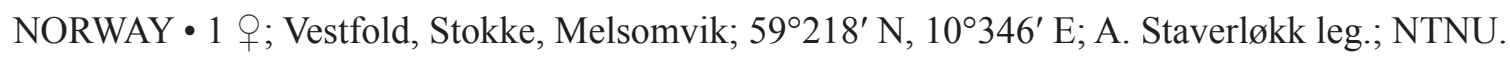

\section{Distribution}

Widely spread across all of the Palaearctic region, from Europe to Russian Far East, South Korea and Japan (Olmi \& Xu 2015; Kim \& Lee 2016). Probably present in northeastern China, but not found so far. 
Aphelopus prolatus Mita \& Olmi, 2014

\section{Material examined}

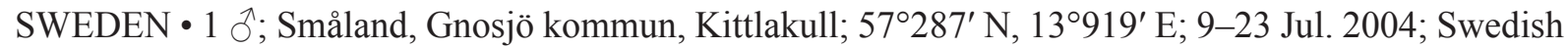
Malaise Trap Project leg.; NHRS.

\section{Discussion}

In the present study, we discovered that $A$. incognitus Chen, Olmi \& Guglielmino sp. nov. shows an evident sexual dimorphism in head colour pattern (female with largely testaceous head, while male with head black), but the $C O I$ sequences generated from female and male specimens allowed us to confirm their association. In A. nivealis and A. zaifui Olmi, Chen \& Liu sp. nov., notauli seem to be variable in appearance and length, but $C O I$ sequences indicated that these variations are just intraspecific. Considering that colour patterns and the length of the notauli have previously been used to separate most species of Aphelopus, the validity of these species should be tested by other methods such as rearing and DNA barcoding.

Our current study demonstrates that DNA barcoding is a powerful tool to enhance species delimitation and the female-male association of the same species. A more complete DNA barcode database of Dryinidae would also accelerate the discovery of host-Dryinidae associations using molecular methods (Chen et al. 2020; Olmi et al. 2021).

\section{Acknowledgements}

Thanks to Drs Li Ma (Yunnan Agricultural University), Jie Zeng (Southwest Forestry University), and Shi-xiao Luo (South China Botanical Garden, Chinese Academy of Sciences) for providing some of the studied specimens. This study was partly supported by the National Natural Science Foundation of China (No. 31472027). The material from Norway and Sweden was obtained from the project INVENT-ART funded by the Norwegian Taxonomy Initiative and the Swedish Malaise Trap Project, respectively. DNA barcode data from Norway and Sweden were generated in collaboration with the Norwegian Barcode of Life Network (NorBOL), funded by the Research Council of Norway and the Norwegian Biodiversity Information Centre. Many thanks to two anonymous reviewers for their precious comments and suggestions. This research was carried out in the frame of the MIUR (Italian Ministry for Education, University and Research) initiative "Department of excellence" (Law 232/2016).

\section{References}

Barthélémy C. \& Olmi M. 2019. Checklist of Dryinidae and Sclerogibbidae (Hymenoptera, Chrysidoidea) from Hong Kong. Zootaxa 4615 (3): 529-548. https://doi.org/10.11646/zootaxa.4615.3.7

Bergman B.H.H. 1957. A new dryinid parasite of leafhoppers in Java. Entomologische Berichten 17: $9-12$.

Chen H.-Y., Olmi M., Pang H. \& Liu J.-X. 2020. Application of DNA barcoding confirms the host of Gonatopus viet Olmi, 1986 (Hymenoptera, Dryinidae). ZooKeys 944: 115-120. https://doi.org/10.3897/zookeys.944.53054

Dalman J.W. 1823. Analecta Entomologica. Typis Lindhianis, Stockholm [Holmiae], Sweden. https://doi.org/10.5962/bhl.title.66069

Folmer O., Black M., Hoch W., Lutz R. \& Vrijenhoek R. 1994. DNA primers for amplification of mitochondrial cytochrome c oxidase subunit I from diverse metazoan invertebrates. Molecular Marine Biology and Biotechnology 3: 294-299. 
Guglielmino A., Olmi M. \& Bückle C. 2013. An updated host-parasite catalogue of world Dryinidae (Hymenoptera: Chrysidoidea). Zootaxa 3740 (1): 1-113. https://doi.org/10.11646/zootaxa.3740.1.1

Guglielmino A., Olmi M., Marletta A. \& Xu Z. 2017. Description of Aphelopus fuscoflavus, a new species of Dryinidae from Thailand (Hymenoptera, Chrysidoidea). Journal of Hymenoptera Research 57: 115-121. https://doi.org/10.3897/jhr.57.12462

Hebert P.D.N., Cywinska A., Ball S.L. \& Dewaard J.R. 2003a. Biological identifications through DNA barcodes. Proceedings of the Royal Society B: Biological Sciences 270: 313-321.

https://doi.org/10.1098/rspb.2002.2218

Hebert P.D.N., Ratnasingham S. \& Dewaard J.R. 2003b. Barcoding animal life: cytochrome $c$ oxidase subunit 1 divergences among closely related species. Proceedings of the Royal Society of London Series B: Biological Sciences 270: S96-S99. https://doi.org/10.1098/rsbl.2003.0025

Kawada R., Lanes G.O. \& Azevedo C.O. 2015. Evolution of metapostnotum in flat wasps (Hymenoptera, Bethylidae): implications for homology assessments in Chrysidoidea. PLoS ONE 10 (10): e0140051. https://doi.org/10.1371/journal.pone.0140051

Kim C.J. \& Lee J.W. 2016. A taxonomical review of the genus Aphelopus (Hymenoptera: Dryinidae: Aphelopinae) from South Korea. Animal Systematics, Evolution and Diversity 32 (3): 159-168. https://doi.org/10.5635/ASED.2016.32.3.002

Kumar S., Stecher G. \& Tamura K. 2016. MEGA7: molecular evolutionary genetics analysis version 7.0 for bigger datasets. Molecular Biology and Evolution 33 (7): 1870-1874.

https://doi.org/10.1093/molbev/msw054

Mita T. \& Matsumoto Y. 2012. First description of the male of Gonatopus javanus (R.C.L. Perkins) determined by mitochondrial COI sequence (Hymenoptera: Dryinidae). Entomological Science 15: 214-218. https://doi.org/10.1111/j.1479-8298.2011.00502.x

Mita T. \& Olmi M. 2014. A taxonomic study of Aphelopus Dalman from Japan, with descriptions of two new species (Hymenoptera: Dryinidae: Aphelopinae). Esakia 54: 91-101.

Mita T., Sanada-Morimura S., Matsumura M. \& Matsumoto Y. 2013. Genetic variation of two apterous wasps Haplogonatopus apicalis and H. oratorius (Hymenoptera: Dryinidae) in East Asia. Applied Entomology and Zoology 48 (2): 119-124. https://doi.org/10.1007/s13355-012-0160-4

Olmi M. 1984. A revision of the Dryinidae (Hymenoptera). Memoirs of the American Entomological Institute 37: i-xii + 1-1913.

Olmi M. 1991. Supplement to the revision of the world Dryinidae (Hymenoptera Chrysidoidea). Frustula entomologica (N.S.) 12: 109-395.

Olmi M. 2010. A contribution to the knowledge of Dryinidae from the Oriental, Nearctic, Neotropical and Australian regions (Hymenoptera Chrysidoidea). Frustula entomologica (N.S.) 31: 11-34.

Olmi M. \& Xu Z. 2015. Dryinidae of the Eastern Palaearctic region (Hymenoptera: Chrysidoidea). Zootaxa 3996 (1): 1-253. https://doi.org/10.11646/zootaxa.3996.1.1

Olmi M., Copeland R.S. \& van Noort S. 2019. Dryinidae of the Afrotropical region (Hymenoptera, Chrysidoidea). Zootaxa 4630 (1): 1-619. https://doi.org/10.11646/zootaxa.4630.1.1

Olmi M., Mita T., Guglielmino A., Vollaro M. \& Vári G. 2021. Application of DNA barcoding confirms the female, male, larva and host of Bocchus scobiolae Nagy, 1967 (Hymenoptera: Dryinidae). Zootaxa 4969 (3): 563-572. https://doi.org/10.11646/zootaxa.4969.3.8 
Perkins R.C.L. 1905. Leafhoppers and their natural enemies (Pt. I. Dryinidae). Report of Work of the Experiment Station of the Hawaiian Sugar Planters' Association, Division of Entomology, Bulletin 1 (i): 1-69. https://doi.org/10.5962/bhl.title.8564

Perkins R.C.L. 1912. Parasites of the Family Dryinidae. Report of Work of the Experiment Station of the Hawaiian Sugar Planters'Association, Division of Entomology, Bulletin 11: 5-20.

Ratnasingham S. \& Hebert P.D.N. 2007. BOLD: the Barcode of Life Data System (www.barcodinglife.org). Molecular Ecology Notes 7: 355-364.

https://doi.org/10.1111/j.1471-8286.2007.01678.x

Richards O.W. 1939. The British Bethylidae (s.1.) (Hymenoptera). The Transactions of the Royal Entomological Society of London 89: 185-344. https://doi.org/10.1111/j.1365-2311.1939.tb00740.x

Taekul C., Valerio A.A., Austin A.D., Klompen H. \& Johnson N.F. 2014. Molecular phylogeny of telenomine egg parasitoids (Hymenoptera: Platygastridae s.1.: Telenominae): evolution of host shifts and implications for classification. Systematic Entomology 39: 24-35. https://doi.org/10.1111/syen.12032

Tribull C.M. 2015. Phylogenetic relationships among the subfamilies of Dryinidae (Hymenoptera, Chrysidoidea) as reconstructed by molecular sequencing. Journal of Hymenoptera Research 45: 15-29. https://doi.org/10.3897/JHR.45.5010

Westwood J.O. 1833. Notice of the habits of a cynipideous insect, parasitic upon the rose louse (Aphis rosae); with descriptions of several other parasitic Hymenoptera. The Magazine of Natural History 6: 491-497. Available from https://www.biodiversitylibrary.org/part/37016 [accessed 22 Nov. 2021].

Xu Z. \& He J. 1999. Three new species of the genus Aphelopus Dalman (Hymenoptera: Dryinidae). Entomologia Sinica 6 (1): 1-4.

Xu Z., He J. \& Yao S. 1997. Descriptions of three new species of the genus Aphelopus Dalman from Mt. Fangjingshan, China. Zoological Research 18 (1): 7-11.

Xu Z., He J. \& Olmi M. 1998. New species of Dryinidae from China (Hymenoptera, Chrysidoidea). Phytophaga 8: 21-37.

Xu Z., He J. \& Olmi M. 1999. Five new species of Aphelopus Dalman from China (Hymenoptera: Dryinidae). Oriental Insects 33: 85-94.

Xu Z., Olmi M., Guglielmino A. \& Chen H. 2011. Description of Aphelopus mangshanensis, a new species of Dryinidae from China. Bulletin of Insectology 64 (2): 243-246.

Xu Z., Olmi M. \& He J. 2013. Dryinidae of the Oriental region (Hymenoptera: Chrysidoidea). Zootaxa 3614 (1): 1-460. https://doi.org/10.11646/zootaxa.3614.1.1

Manuscript received: 16 May 2021

Manuscript accepted: 11 November 2021

Published on: 14 February 2022

Topic editor: Nesrine Akkari

Section editor: Gavin Broad

Desk editor: Pepe Fernández

Printed versions of all papers are also deposited in the libraries of the institutes that are members of the EJT consortium: Muséum national d'histoire naturelle, Paris, France; Meise Botanic Garden, Belgium; Royal Museum for Central Africa, Tervuren, Belgium; Royal Belgian Institute of Natural Sciences, Brussels, Belgium; Natural History Museum of Denmark, Copenhagen, Denmark; Naturalis Biodiversity 
Center, Leiden, the Netherlands; Museo Nacional de Ciencias Naturales-CSIC, Madrid, Spain; Real Jardín Botánico de Madrid CSIC, Spain; Zoological Research Museum Alexander Koenig, Bonn, Germany; National Museum, Prague, Czech Republic.

\section{Supplementary file}

Supp. file 1. Genetic distances between COI sequences. https://doi.org/10.5852/ejt.2022.794.1653.5975 